Review Article

\title{
Comparing the Therapeutic Potential of Stem Cells and their Secretory Products in Regenerative Medicine
}

\author{
Jhi Biau Foo, ${ }^{1,2}$ Qi Hao Looi, ${ }^{3}$ Pan Pan Chong, ${ }^{4}$ Nur Hidayah Hassan, ${ }^{4,5}$ \\ Genieve Ee Chia Yeo, ${ }^{6}$ Chiew Yong $\mathrm{Ng}^{6}{ }^{\text {Benson Koh, }}{ }^{6}$ Chee Wun How, ${ }^{7}$ Sau Har Lee, ${ }^{2,8}$ \\ and Jia Xian Law ${ }^{6}{ }^{6}$ \\ ${ }^{1}$ School of Pharmacy, Faculty of Health and Medical Sciences, Taylor's University, 47500 Subang Jaya, Selangor, Malaysia \\ ${ }^{2}$ Centre for Drug Discovery and Molecular Pharmacology (CDDMP), Faculty of Health and Medical Sciences, Taylor's University, \\ 47500 Subang Jaya, Selangor, Malaysia \\ ${ }^{3}$ My Cytohealth Sdn Bhd, Bandar Seri Petaling, 57000 Kuala Lumpur, Malaysia \\ ${ }^{4}$ National Orthopaedic Centre of Excellence for Research and Learning (NOCERAL), Department of Orthopaedic Surgery, \\ Faculty of Medicine, Universiti Malaya, 50603 Kuala Lumpur, Malaysia \\ ${ }^{5}$ Institute of Medical Science Technology, Universiti Kuala Lumpur, 43000 Kajang, Selangor, Malaysia \\ ${ }^{6}$ Centre for Tissue Engineering and Regenerative Medicine, Faculty of Medicine, Universiti Kebangsaan Malaysia Medical Centre, \\ Jalan Yaacob Latif, 56000 Kuala Lumpur, Malaysia \\ ${ }^{7}$ School of Pharmacy, Monash University Malaysia, 47500 Bandar Sunway, Selangor, Malaysia \\ ${ }^{8}$ School of Biosciences, Faculty of Health and Medical Sciences, Taylor's University, 47500 Subang Jaya, Malaysia
}

Correspondence should be addressed to Jia Xian Law; lawjx@ppukm.ukm.edu.my

Received 14 May 2021; Accepted 28 July 2021; Published 20 August 2021

Academic Editor: Kar Wey Yong

Copyright (C) 2021 Jhi Biau Foo et al. This is an open access article distributed under the Creative Commons Attribution License, which permits unrestricted use, distribution, and reproduction in any medium, provided the original work is properly cited.

Cell therapy involves the transplantation of human cells to replace or repair the damaged tissues and modulate the mechanisms underlying disease initiation and progression in the body. Nowadays, many different types of cell-based therapy are developed and used to treat a variety of diseases. In the past decade, cell-free therapy has emerged as a novel approach in regenerative medicine after the discovery that the transplanted cells exerted their therapeutic effect mainly through the secretion of paracrine factors. More and more evidence showed that stem cell-derived secretome, i.e., growth factors, cytokines, and extracellular vesicles, can repair the injured tissues as effectively as the cells. This finding has spurred a new idea to employ secretome in regenerative medicine. Despite that, will cell-free therapy slowly replace cell therapy in the future? Or are these two modes of treatment still needed to address different diseases and conditions? This review provides an indepth discussion about the values of stem cells and secretome in regenerative medicine. In addition, the safety, efficacy, advantages, and disadvantages of using these two modes of treatment in regenerative medicine are also critically reviewed.

\section{Introduction}

Cellular therapy, also known as "cell-based therapy," involves the transplantation of human cells to stimulate the regeneration of damaged tissues and modulate the mechanisms underlying disease initiation and progression. Multiple types of human cells, including stem cells and progenitor cells, have been used to treat different diseases. Stem cell therapies using induced pluripotent stem cells (iPSCs) [1], embryonic stem cells (ESCs) [2], and adult stem cells such as mesenchymal stem cells (MSCs) [3] have been tested preclinically and clinically for years. Nowadays, MSC is widely used in the field of tissue engineering and regenerative medicine. In general, stem cell therapy has grown to become an attractive option to reduce the overall need for tissue transplantation and minimize the waiting time for patients [4]. Numerous clinical studies have indicated that stem cell administration is a safe and promising therapeutic approach. The transplanted cells 
can differentiate to restore the structure and function of injured tissues $[5,6]$. However, more and more evidence suggested that the transplanted cells promote tissue regeneration mainly through paracrine secretion.

Recent studies have shown that the transplanted cells secrete paracrine factors that directed the proliferation and differentiation of surrounding cells as well as produce chemoattractants that attracted the migration of effector cells to the injured sites. The "cell-free therapy" that utilizes the therapeutic molecules, i.e., secretome, secreted by stem cells has become more popular as it offers many advantages and avoids many limitations bothering the cell-based therapy. The composition of secretome is very dynamic, depending on the cell type and stimulus from their surrounding microenvironment [7]. Generally, stem cell-secreted secretome comprises (i) a complex mixture of soluble components such as growth factor and cytokines (obtained as the conditioned medium), (ii) a vesicular portion composed of extracellular vehicles (EVs), and (iii) cell organelles (e.g., mitochondria). It has been suggested that secretome can promote cell-cell communication, interact with other cells in their immediate environment, and transfer functional biomolecules to initiate tissue repair or regeneration. Generally, secretome has been found to possess proangiogenic, antiapoptotic, antifibrotic, anti-inflammatory, immunomodulatory, and proproliferative properties [8-10]. Nevertheless, extensive investigations are still required to better understand the therapeutic mechanism of secretome transplantation, its safety issues, and the clinical efficacy, mainly through clinical trials. In this review, the focus is on the values of stem cells and secretome in regenerative medicine, as well as discussing the latest insights on the safety, efficacy, advantages, and disadvantages of using these two modes of treatment.

\section{Classification of Cell-Based Therapy}

2.1. Stem Cell Therapy. Stem cell therapy can be categorized into autologous and allogeneic based on the tissue donor. To date, autologous stem cell transplantation has been performed for a broad range of purposes, such as to promote cardiac and cartilage regeneration, expedite wound healing, and improve aesthetic appearance. Autologous stem cells are used as they are readily available from many tissue sources and have a lower risk of life-threatening complications such as graftversus-host disease (GVHD), free of ethical issues, and nonimmunogenic. The adverse events reported in the transplantation of stem cells are most likely unrelated to the treatment but to the underlying disease instead [11].

Allogeneic stem cell transplantation is gaining more attention in the past decade due to its advantages, such as reduction of functional variability through the pooling of cell products from multiple donors in a master bank, and it is readily available off-the-shelf for clinical applications. Allogeneic bone marrow-derived MSCs (BMSCs) mixed with autologous chondrocytes have been transplanted into the knee joint of patients with symptomatic cartilage defect, and the results showed the regeneration of hyaline cartilage with a high concentration of proteoglycans and type II collagen at 12 months [12]. A clinical trial on end-stage liver cir- rhosis also revealed that allogeneic stem cell transplantation positively affects the patients' condition by improving the serum albumin levels and model for end-stage liver disease (MELD) scores after six months [13]. Paul et al. reported the immunomodulatory benefit of allogeneic MSC infusion by reducing the rejection of transplanted corneal during the immediate posttransplant period [14].

2.2. Stem Cell Derivatives/Secretome. In the field of regenerative medicine, the therapeutic effects of stem cells are not constricted to cell-cell interactions. A broad range of bioactive molecules is found in stem cell secretion, including growth factors, cytokines, chemokines, enzymes, extracellular matrix (ECM), and extracellular vesicles (EVs), collectively known as the secretome [15]. The secretome is a crucial component in exhibiting the therapeutic effect of stem cells (Figure 1).

\section{Stem Cells}

3.1. Source of Stem Cells. The collection of pluripotent stem cells (PSCs) such as ESCs is ethically controversial as it involves the destruction of possible human life. Furthermore, ESC is also considered an allogeneic source of cells which may cause immune incompatibility. However, there is an immediate solution to avoid ethical repercussions; the adult somatic cells can be reprogrammed into iPSCs which essentially functionally behaved as ESCs [16]. Genetically modified PSC is utilized in disease modeling to overcome the species-specific differences as observed in an animal model. It also serves as a potential cure to a currently permanent condition such as thyroid disease [17-19], cardiovascular disease [20], macular degeneration [21, 22], or Parkinson's disease that only can be managed with lifelong medications. Unfortunately, PSC has raised safety concerns as some research reported tumorigenicity [23] or epigenetic aberrations posttreatment [24-26]. A fail-safe suicide gene known as inducible caspase-9 (iCasp9) has been tested extensively in vitro and in vivo as a potentially viable solution to remove the residual pluripotent cell that may cause teratoma formation $[27,28]$.

On the other hand, multipotent cells have a narrower spectrum of differentiation than pluripotent stem cells and can differentiate into discrete cells of specific lineages. Examples of multipotent cells are hematopoietic stem cells (HSCs) and MSCs. HSCs can be isolated from peripheral blood, bone marrow, and umbilical cord blood, whereas MSCs can be found in bone marrow, umbilical cord, cord blood, placental, peripheral blood, adipose tissue, dental tissues, skin, salivary gland, and synovial fluid [29-32]. Although there are variations in molecular composition, surface antigen expression, differentiation capacity, and immunomodulatory property in MSCs isolated from different tissue sources [23, 33], however, functional analyses showed that all the secretome have similar functionality, i.e., to promote cell migration and inhibit cell apoptosis [34].

3.2. Mechanism of Therapeutics. MSCs were thought to promote tissue regeneration via transdifferentiation to replace 


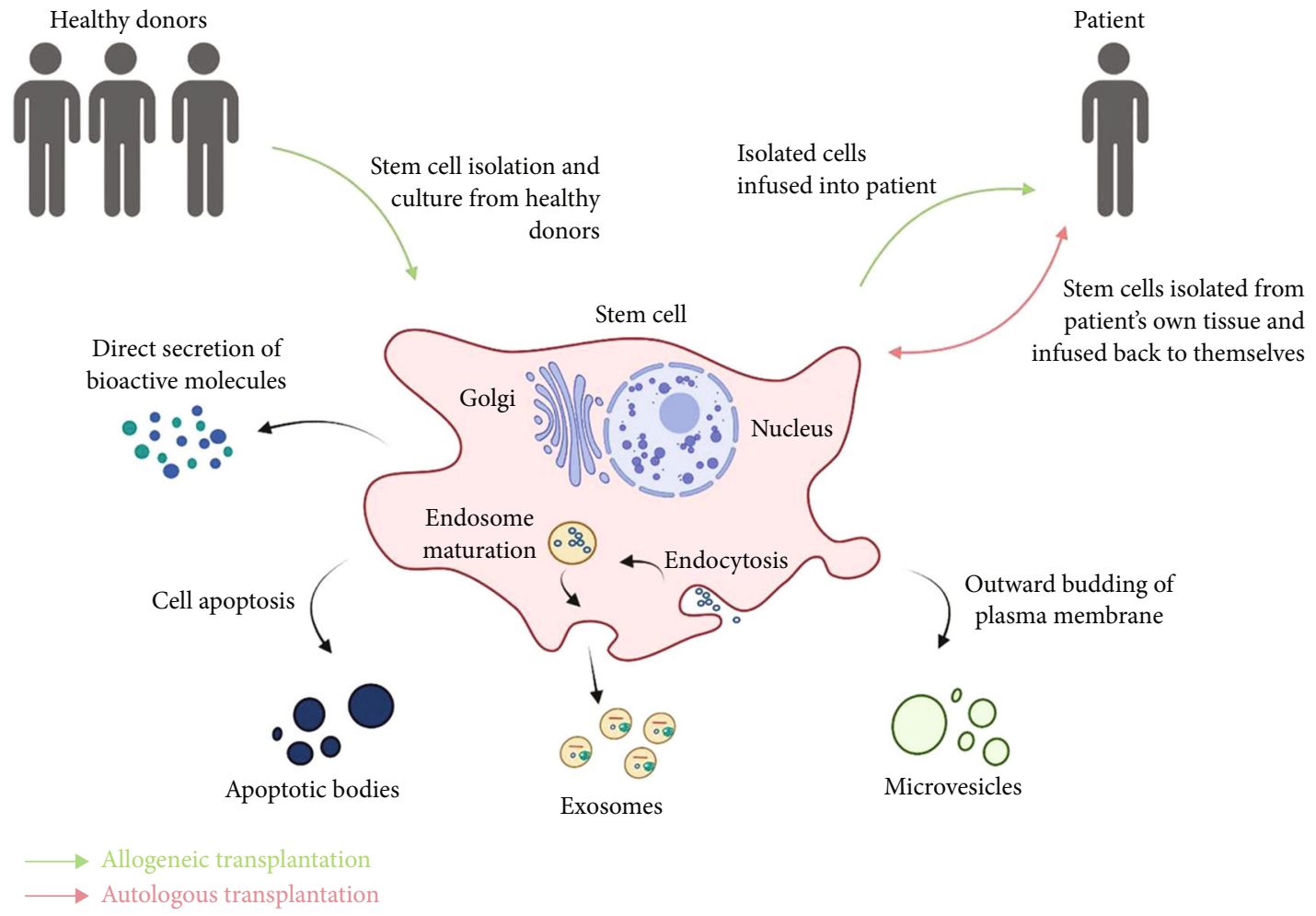

FIGURE 1: Classification of stem cell therapy and stem cell-derived secretome. Autologous stem cell transplantation involves the isolation of stem cells from the patient and infusion back to the same patient during treatment. Whereas in allogeneic stem cell transplantation, stem cells from single or multiple healthy donors are given to the patient. Stem cell secretome consists of bioactive molecules (including growth factors, cytokines, chemokines, enzymes, extracellular matrix) secreted directly out to the cell microenvironment or encapsulated within the extracellular vesicles that can be classified into three groups: apoptotic bodies which form during cell apoptosis, exosomes as the product of endosome maturation, and microvesicles by outward budding of the plasma membrane (created with BioRender.com).

the damaged cells and cell fusion to save the dying cells. However, many studies have found that these mechanisms are insufficient, and MSCs seem to secrete a myriad of paracrine factors, e.g., growth factors, chemokines, and cytokines, to promote tissue regeneration and modulate the immune response. This notion is supported by the low engraftment of the transplanted cells at the target site and rapid loss of the transplanted cells in vivo. The mechanisms employed by MSCs in tissue repair and immunomodulation have been excellently reviewed in previous publications [3539]. In this section, we will only provide a glimpse at their mechanism of action in a short summary. In brief, MSCs secrete anti-inflammation, antiapoptosis, antioxidative, antifibrosis, proangiogenesis, promitosis, and chemotactic factors to stimulate tissue regeneration (Figure 2).

\subsection{Multifactorial Crosstalk}

3.3.1. Direct Signaling. Cell-cell signaling by direct contact allows stem cells to communicate and respond to other cells. It is not always necessary as stem cells have other solubledependent crosstalk as well. In a mixed immune cell culture such as peripheral blood mononuclear cells (PBMCs), cell contact is not required for MSCs to exert their antiinflammatory effect. Contrastingly, when MSCs were introduced to a lymphocyte-only culture and cell-cell contact was prohibited, MSCs failed to induce FoxP3 and CD25 expressions in $\mathrm{CD}^{+} \mathrm{T}$ cells [40]. The adhesion molecules ICAM-1 and VCAM-1 will not form in the lack of direct MSC-lymphocyte contact [41]. Moreover, MSCs require direct contact with immune cells to upregulate cell-surface proteins such as programmed death-ligand 1 (PD-L1) and Fas ligand to suppress inflammation $[42,43]$. As a result, the immunoregulatory properties of MSC will not be exerted to their full potential. The modulation of dendritic cell maturation by MSCs also requires both direct cellular contact and the soluble factor, interleukin (IL)-6. Loibl et al. reported better results when endothelial progenitor cells were cocultured with MSCs as it significantly upregulated the mature endothelial cell marker, PECAM-1, relative to the transwell setup [44]. The immunosuppression of B cells was more efficient in direct cocultured with MSCs [45].

3.3.2. Secondary Crosstalk. Paracrine signaling is the main mechanism of MSC therapy. It was initially thought that MSC would migrate and engraft at the site of injury. Nonetheless, most of the MSC administrated intravenously are sequestered in the vasculature of the lungs, with only a few MSCs homed to the tissue of interest. Studies have also noted that exogenous MSCs unable to retain their population long enough to completely replace the affected tissue. Hence, the lasting reparative effect of MSCs is largely attributed to its 


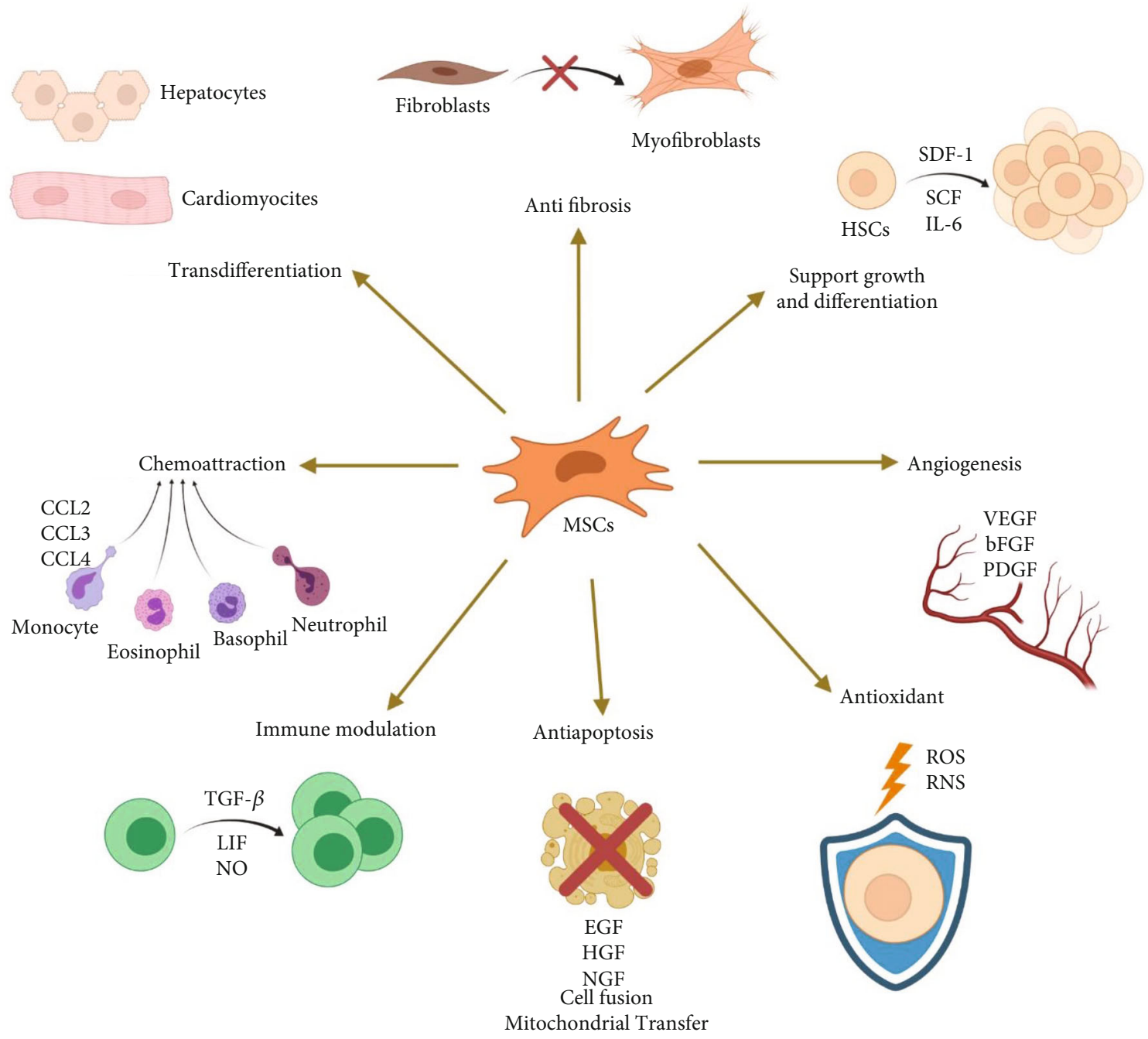

FIGURE 2: Mechanism of action of MSCs in tissue repair and immunomodulation. MSCs exert its therapeutic effects via various modulators. SDF-1: stromal cell-derived factor 1; SCF: stem cell factor; IL-6: interleukin-6; VEGF: vascular endothelial growth factor; bFGF: basic fibroblast growth factor; PDGF: platelet-derived growth factor; ROS: reactive oxygen species; RNS: reactive nitrogen species; EGF: epidermal growth factor; HGF: hepatocyte growth factor; NGF: nerve growth factor; TGF- $\beta$ : transforming growth factor-beta; LIF: leukemia inhibitory factor; NO: nitric oxide; CCL: C-C motif chemokine ligand (created with BioRender.com).

ability to secrete trophic factors to ameliorate the inflammation in other parts of the body $[35,46-48]$. Chin et al. claimed that the anti-inflammatory cytokine levels remained elevated from baseline up until six months post-MSC transfusion [46]. MSCs are known to secrete immunosuppressive factors such as transforming growth factor-beta (TGF- $\beta$ ), vascular endothelial growth factor (VEGF), IL-10, prostaglandin E2 (PGE2), indoleamine 2,3-dioxygenase (IDO), and galectin-1 into the circulatory system [47-51]. These molecules interact with the immune cells such as $\mathrm{T}$ and $\mathrm{B}$ cells to suppress their proliferation and differentiation, causing the polarization of macrophage to an anti-inflammatory phenotype and reduction of the pro-inflammatory milieu consists of cytokines such as tumor necrosis factor-alpha (TNF- $\alpha$ ), interferongamma (IFN- $\gamma$ ), and IL-6 [46, 47, 49, 52-55].

3.3.3. Necrobiology. Necrobiology is a term used to describe the life processes associated with morphological, biochemical, and molecular changes related to cell death and the consequences and tissue response to cell death [56]. It encompasses four mechanisms by which derivatives of MSCs can retain significant clinical efficacy, including apoptosis, autophagy, mitochondrial transfer, and extracellular vesicle production [57]. The bioactive parts of dead or dying MSCs can trigger immunomodulatory properties in the host without the concern over cell survival and the formation of large aggregates [58-60].

(1) Apoptosis. Apoptosis of cultured MSCs can be induced via nutrient deprivation. In addition, some studies found that IFN- $\gamma$ and TNF- $\alpha$ also can trigger MSC apoptosis through the nitric oxide (NO) [61] and Fas [62] pathways, respectively. One can consider inhibiting NO to prolong MSC survival, noting that it also will restrict the immunosuppression capacity of MSCs on the lymphocytes. Interestingly, Mancuso et al.'s study of knee osteoarthritis using an in vitro model revealed that apoptotic MSCs were more immunosuppressive than healthy MSCs [63]. Moreover, Chang et al. 
found that apoptotic MSCs were more effective in attenuating organ damage in rat sepsis models compared to the healthy MSCs [64]. Cheung et al. found that monocytes that efferocytosed the apoptotic MSCs have higher expression of IDO, PD-L1, and cyclooxygenase 2 (COX2), and these cells secrete more PGE2 and IL-10 as well as lower TNF- $\alpha$ to subside the inflammation. Then, they proceeded to monitor the serum PGE2 levels of eight patients with severe steroidresistant GVHD who received MSC therapy. It was found that the responders demonstrated increment in PGE2 levels while the nonresponders showed not changes in PGE2 levels. Albeit, in a small sample size of eight GVHD patients, this study teased the possibility of apoptotic MSCs in translational medicine [65].

(2) Autophagy. In terms of stem cells, autophagy plays a pivotal role in maintaining genomic stability and retain its potency and differentiation capacity [66]. Gao et al. discovered that autophagy may regulate MSC immunoregulation through TGF- $\beta 1$ signaling. The proliferation of $\mathrm{CD}^{+} \mathrm{T}$ helper cells was inhibited when cocultured with autophagic MSCs. However, when autophagy is inhibited, MSCs failed to suppress the proliferation of T cells [67]. Additionally, autophagy activation in MSC transplantation has protective effects on the damaged tissues. These protective effects of autophagy can be reversed using autophagy inhibitors such as 3-methyladenine and chloroquine. Autophagy can be induced by hypoxia and nutrient depletion, and it has been shown to protect MSCs in vitro [68]. Furthermore, Zhang et al. showed that hypoxic preconditioning on MSCs can enhance its functional survival to restore cardiac function in ischemia models [69]. Using rapamycin to induce the autophagy mechanism, Wang et al. showed that MSCderived exosomes prevented acute kidney injury caused by cisplatin [70]. Similarly, Hou et al. induced autophagy by pretreating MSCs with starvation and rapamycin. In their study, it was shown that autophagy prevented the autophagic MSCs from irradiation injury and maintained the stemness after exposure to reactive oxygen species- (ROS-) induced damage [71]. Park et al. attributed the neuroprotective effects of MSCs to the higher levels of autophagy in a parkinsonian mice model and $\mathrm{MPP}^{+}$treated neuronal cell culture [72].

(3) Mitochondrial Transfer. MSCs are known to reprogram the host cells by the transfer of mitochondria. It is a process that requires direct cell-cell contact through tunneling nanotubes (TNT) or gap junctions [73]. Mitochondria also can be transferred via secreted EVs [56]. The mitochondrial transfer has a prominent role in protecting the recipient cells from oxidative stress, radiation injury, and hypoxic injury as well as recovering the mitochondrial membrane potential and aerobic respiration and modulating the host immune response [74, 75]. Upregulation of Miro 1, a mitochondrial Rho-GTPase, has been reported to enhance mitochondrial transfer, subsequently improve the MSC therapeutic efficacy [76].

(4) Extracellular Vesicles. According to MISEV 2018, EVs are nonreplicating particles of size 100-200 $\mathrm{nm}$ and encapsulated by a lipid bilayer [77]. MSC-derived EVs contain bioactive molecules including genetic materials, microRNAs, enzymes, signaling proteins, immunomodulatory factors, and growth factors [78]. EVs have the potential to be developed into cell-free therapy with the benefits of MSC immunomodulation but without the concerns of maintaining the cell viability or risk of immune rejection in allogeneic transplantation. Many studies showed that MSC-derived EVs are as effective as MSCs in treating diseases [79-81]. Apoptotic cells are known to produce different types of EVs and apoptotic bodies that can influence the surrounding cells. Apoptotic cellderived EVs are rich in spliceosomes that alter the RNA splicing in recipient cells [82]. More data are showing that apoptotic cell-derived EVs play a significant role in immune modulation in autoimmunity, infection, and cancer, implicating that they are not just cell debris [83]. All these findings indicating that apoptotic cell-derived EVs could be an important medium of communication between the dead and living cells [84]. Nonetheless, to date, apoptotic cell-derived EVs are not well studies. Thus, what we know is still very limited.

\section{Secretome}

Secretome is often referred as a group of biologically active molecules or factors that are released by cells into their extracellular environment [85]. Although MSCs derived from various anatomical sites may exhibit similar morphological and immunophenotypic characteristics, numerous evidence showed that they secrete a distinct set of secretome that is normally associated with the host age and specific microenvironment that the cells were grown. The secretome may even fluctuate in response to various physiological changes and pathological circumstances. In general, MSC secretome is made up of a variety of growth factors, cytokines, and EVs that conferred its tissue repair and regenerative potential, mainly attributed to their capability to stimulate cell proliferation, formation of new blood vessels, and their immunomodulatory effects (Figure 3) $[85,86]$.

4.1. Growth Factor. Different investigations have shown that the growth factors present in MSC secretome may either work synergistically to exert their tissue regenerative potential or the presence of individual growth factors could be sufficient to achieve the desired therapeutic objective. For instance, brain injury such as stroke usually involves brain tissue damage due to a lack of blood supply. Hence, stroke therapy usually requires the promotion of new blood vessel formation and brain cell production, along with suppression of further cell death and inflammatory processes [85]. These have been successfully achieved via administration of BMSC and adipose tissue-derived MSC (AT-MSC) secretome that contain a mixture of hepatocyte growth factor (HGF), brain-derived neurotrophic factor (BDNF), fibroblast growth factors (FGF), and platelet-derived growth factor (PDGF) [7, 87]. Meanwhile, another study by Ding et al. has suggested a direct involvement of increased insulin-like growth factor-1 (IGF-1) levels that exhibited neuroprotective effect in a mouse model of brain stroke through regulating its ischemic and inflammatory condition to reduce the volume of brain infarct while improving the function of brain cells [88]. 


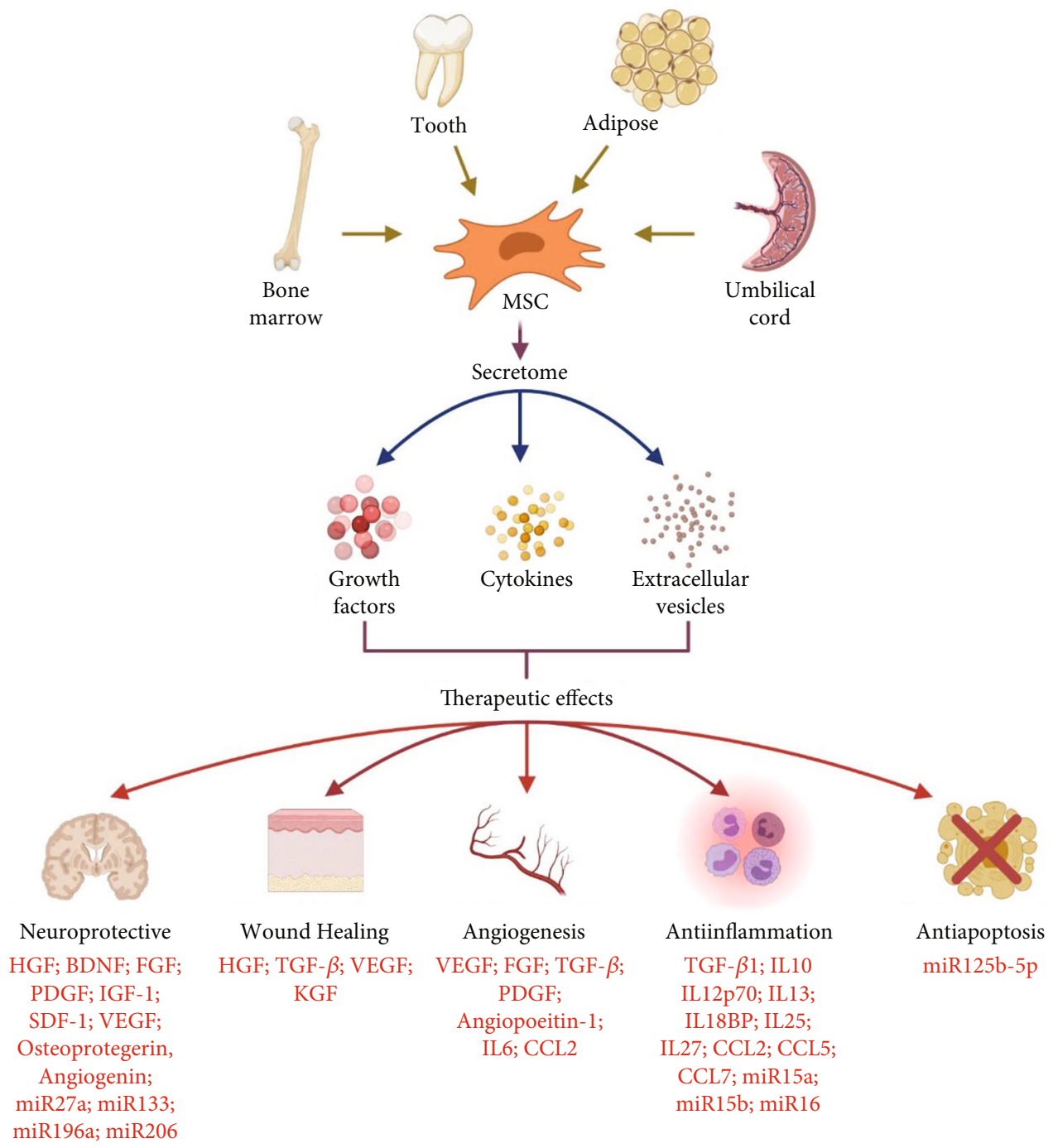

FIGURE 3: Mesenchymal stem cell sources, secretome content, and its therapeutic effects. MSCs can be derived from various sources, including bone marrow, teeth (deciduous vs. nondeciduous), adipose tissue, and umbilical cord. MSCs mainly rely on the secretome, which consists of various soluble factors (growth factors and cytokines) and extracellular vesicles to exert their therapeutic effects. Neuroprotection, acceleration of wound healing, induction of angiogenesis, suppressing of inflammation, and prevention of cell apoptosis are some of the reported therapeutic potentials of MSC secretome. HGF: hepatocyte growth factor; BDNF: brain-derived neurotrophic factor; FGF: fibroblast growth factor; PDGF: platelet-derived growth factor; IGF-1: insulin-like growth factor 1; SDF-1: stromal cell-derived factor 1; VEGF: vascular endothelial growth factor; TGF- $\beta$ : transforming growth factor-beta; KGF: keratinocyte growth factor; IL: interleukin; miR: microRNA; CCL: C-C motif chemokine ligand (created with BioRender.com).

Similar observations also have been reported in Huntington's disease mouse model whereby transplantation of BMSCs led to elevated expression of stromal cell-derived factor-1 (SDF1) to improve blood supply to the damaged brain striatum tissue via stimulation of angiogenesis [89]. The neuroprotective role of SDF-1 had also been verified in another rat model of Parkinson's disease whereby the grafted BMSCs inhibited apoptotic activities in the affected dopaminergic neuronal tissue, which significantly recovered the behavior of the diseased rats [90]. Besides brain injuries, therapeutic effects of growth factors present in MSCs have also been investigated for other pathologic conditions such as cutaneous injury, whereby the use of AT-MSC secretome that contains VEGF, $\mathrm{HGF}$, transforming growth factor $\beta$ (TGF- $\beta$ ), and keratinocyte growth factor (KGF) was able to induce greater cellular proliferation, trigger cell migration, and decrease the wound size at a faster rate [91-95]. The positive impact of these diverse growth factors in promoting angiogenesis [96], regenerating muscle tissue [97], and reducing incidences of premature infant diseases such as periventricular leukomalacia, retinopathy of prematurity, bronchopulmonary dysplasia, and necrotizing enterocolitis [98] also has been implicated.

4.2. Cytokines. Whilst growth factors are more frequently associated with induction of cellular proliferation or prevention of cell death for tissue regeneration, cytokines present in the MSC secretome play a more important role in regulating inflammatory activities in pathologic conditions to attain the therapeutic effect. In the MSC secretome, both antiinflammatory cytokines (such as tumor necrosis factor $\beta 1$ 
(TNF- $\beta 1$ ), IL-10, IL-12 p70, IL-13, IL-18 binding protein, IL25 , and IL-27) and proinflammatory cytokines (such as TNF$\alpha$, interferon $\gamma$ (IFN- $\gamma$ ), IL-1b, IL-6, IL-8, and IL-9) could be present. The impact of MSC secretome on the inflammatory process is usually governed by the balance of these anti- and proinflammatory cytokines [86]. For example, the destruction of pancreatic cells in autoimmune diabetes mellitus type 1 disease by proinflammatory cytokines, including TNF- $\alpha$, IFN- $\gamma$, and IL- $1 \mathrm{~b}$, could be reversed by treating the primary islet cells with MSC secretome containing significantly elevated levels of anti-inflammatory cytokines (IL-4 and IL$10)$, resulted in the prevention of cell apoptosis and improvement in insulin secretion [99]. The importance of antiinflammatory cytokines produced by MSCs was further demonstrated by Hsu et al. who utilized MSCs to suppress inflammation-associated transplant arteriosclerosis through the secretion of IL-10 [100]. In another study by Ogata et al., MSC secretome was shown to stimulate bone healing in a rat bone defect model by increasing the migration of endogenous stem cells into the defect area. Subsequent analysis revealed the presence of various important cytokines in the MSC secretome which are essential to suppress inflammation as well as induce cell proliferation, angiogenesis, recruitment, and osteogenesis. These cytokines include chemokine ligand 2 , chemokine ligand 5, chemokine ligand 7 , and TNF- $\beta$ [101].

4.3. Extracellular Vesicles. Other than growth factors and cytokines, EVs are another important subset of MSC secretome that play a crucial role in both normal and pathological processes through maintenance of homeostasis as well as regulation of immune function, tissue regeneration processes, and tumorigenesis. These EVs that carry therapeutic cargo, including nucleic acids, proteins, and lipids, are originally a method of communication between neighboring and distant cells. They can be divided into two types depending on their sizes, that is either exosomes $(40-200 \mathrm{~nm})$ or microvesicles $(50-1000 \mathrm{~nm})$ [4]. Example of the therapeutic proteins abundantly present in EVs secreted by MSCs includes osteoprotegerin and angiogenin that were found to be the key players for bone regeneration in a rat model of bone defect [101]. Besides proteins, microRNAs (miRNAs) inside the EVs secreted by BMSCs, such as miR27a, miR196a, and miR206, were also found to be crucial in triggering the expression of osteogenic genes for acceleration of bone regeneration in a rat model of calvarial bone defect [102]. On the other hand, miR133 is an important miRNA produced by MSCs to stimulate neuronal tissue remodeling in a rat model of stroke disease [103, 104]. Meanwhile, miR125b-5p is an example of miRNA that could exert antiapoptotic effect as demonstrated by its ability to suppress expression of proapoptotic BAK1 and p53 genes in a myocardial infarction model, hence preventing the death of cardiomyocytes and subsequently allowing the repair of the ischemic tissue [105]. Apart from modulation of tissue regeneration, some miRNAs are also able to regulate the immune system to suppress the extent of tissue injury. For instance, miR15a, miR15b, and miR16 could inhibit the expression of CX3CL1 to prevent recruitment of macrophages to the ischemic kidney, therefore reducing the inflammatory process in the injured kidney [106].

\section{Delivery and Homing of Stem Cells and Secretome}

Stem cells and secretome can be delivered via various routes of administration to elicit their therapeutic actions. Thus far, direct injection to the target site and intravenous injection is most widely used as they deliver the biologics to the target tissue more effective compared to other routes of administration.

Compared to exosomes, homing of stem cells to the target tissue is critical for the cells to exert their therapeutic effects. The efficacy of stem cell homing to the target tissue upon transplantation is very much dependent on the route of administration. There is an intrinsic relationship between different chemical factors and MSCs that influence its homing and reparative effects. Stromal-derived factor-1 (SDF-1)/CXC chemokine receptor 4 (CXCR4) axis is imperative in the recruitment of MSCs to the injured tissue $[107,108]$ and inadvertently promotes neovascularization $[109,110]$. The increased expression of SDF-1 after tissue injury stimulates the expression of CXCR4 on MSCs which improve stem cell homing and engraftment to the injured site [111]. Besides, Qin et al. described that SDF-1 regulates the MSC immunomodulatory effects through CXC chemokine receptor 7 (CXCR7). In low concentration, the proliferation of MSCs is induced, and the regulatory $\mathrm{B}$ cells produce various cytokines including (IL-6, IL-10, IL-4, IFN- $\gamma$, TNF- $\alpha$ ) [112]. Zheng et al. suspected enhanced homing of CXCR4-overexpressing MSCs to the site of colitis resulted in the significant reduction of tumor formation when compared to the untreated group [113]. Similarly, Wang et al. observed improvement in cell migration using CXCR4-overexpressing MSCs, and the progression of diabetic retinopathy was hampered [47]. Without CXCR4 gene transfection, MSC is considerably less effective in repairing cardiovascular damage as the necessary vascular cell adhesion molecule-1 (VCAM-1), and intercellular adhesion molecule-1 (ICAM-1) cannot be stimulated solely with SDF-1 $[110,114]$.

5.1. Direct Injection to the Target Tissue. Direct injection is a straightforward approach to deliver stem cells to the target tissue. For example, stem cells can be injected through the intraspinal and intrathecal route to treat spinal cord injury and intraarticularly to treat osteoarthritis $[115,116]$. Direct injection can increase the homing of stem cells to the target tissue, and this is crucial as stem cells can self-renew and differentiate into the desired cells to repopulate and regenerate the injured or lost tissue. In addition, local delivery of stem cells to the target tissue is necessary as the secreted bioactive factors act in a paracrine manner and may be degraded in the bloodstream before reaching the target tissue when administered distantly. In the context of secretome such as exosomes, direct injection is applicable as well. MSC exosomes were effective in repairing critical size osteochondral defects in immunocompetent rats, as evidenced by the increased cellular proliferation and infiltration, enhanced matrix synthesis, 
TABLE 1: Recent studies applied secretome and its components via intravenous (IV) route.

\begin{tabular}{lccc}
\hline Cell type & Disease model & Application method & References \\
\hline Cardiac stem cells & Cardiac myopathy & IV injection of $30 \times 10^{9}$ exosomes & {$[122]$} \\
BMSCs & Pulmonary hypertension & IV injection of culture media $(30 \mu \mathrm{g} / 100 \mu \mathrm{L})$ & {$[123]$} \\
BMSCs & Asthma & IV injection of culture media $(500 \mu \mathrm{g} / \mathrm{mL})$ & {$[124]$} \\
BMSCs & Lung fibrosis & IV injection of $10 \mu \mathrm{g}$ EVs & {$[125]$} \\
MSCs & Myocardial inflammation & IV injection of $200 \mu \mathrm{L}$ of $300 \mu \mathrm{g}$ exosomes & {$[126]$} \\
iPSCs & Limb ischemia & IV injection of $200 \mu \mathrm{g}$ exosomes & {$[127]$} \\
hMSC544 cells & Ovarian cancer & IV injection of $100 \mu \mathrm{L}$ exosomes & {$[128]$} \\
Schwann cells & Peripheral neuropathy caused by type 2 diabetic & IV injection of $200 \mu \mathrm{L}$ exosomes & {$[129]$} \\
BMSCs & COVID-19 & IV injection of 15 mL exosomes
\end{tabular}

and presence of regenerative immune phenotype [117]. These results are achieved via intraarticular injection of exosomes.

Even though many researchers have analyzed the therapeutic efficacy of different routes of delivery for stem cell therapy, however, there is still no congruous consensus on the optimal delivery method among the different reports [118]. Although direct injection of cell-based treatment (either stem cell or secretome) to the affected tissue is appealing and has long been documented, this approach may accompany problematic complications if it is not carefully planned, performed, or managed. The migration of stem cell or lymphatic drainage is the physiological process that would reduce the number of injected cells or quantity of secretome initially present in the target tissue vicinity. In addition, the hostile wound environment with intense inflammation is not ideal to support the survival of the transplanted cells [119].

5.2. Intravenous Administration. Delivery of cells through vein has been suggested in numerous preclinical studies and clinical trials [120]. Intravenous administration is advantageous because of its systemic distribution and ability to reach deeper tissues. However, intravenous administration also carries the risk of cell entrapment in the lung vasculature, and the retention time for the cells and their effects are short. The main concern of intravenous administration is to get enough cells to the target tissues. Harting et al. managed to infuse rats with MSCs intravenously to treat traumatic brain injury [121]. The group did not find cell homing to the target tissue. However, the rats still showed improvement in motor and cognitive functions. In terms of secretome, delivery via the intravenous route is safe due to the lower risk of embolism compared to the delivery of stem cells. In the case of neurological disorders, emboli of administered cells in the cerebral microvascular can exacerbate the disease and can be life-threatening. Intravenous administration of whole secretome or its components, i.e., exosomes, has been reported to be safe and capable to ameliorate several diseases (Table 1).

5.3. Scaffold. On top of that, new delivery strategies utilizing the biomaterials such as polymeric scaffolds and cell sheets can increase cell retention on top of providing a supporting matrix to enhance cell survival and functionality [131]. The polymeric scaffold stabilizes the stem cells and their soluble factors as well as permits sustained delivery of these bioactive factors. The structure also supports cell growth. The architecture of the scaffolds including stiffness and pore arrangement is an important regulator of stem cell differentiation. The microarchitecture of the scaffold has an impact on the differentiation of MSCs into cells of interest. Phadke et al. found the randomly oriented pores were better suited for osteogenic differentiation of MSCs when compared to the lamellar column-arranged pore network [132]. Multiple studies have focused on the development of insulin-producing cells to treat diabetes. Enderami et al. noted a significantly higher expression of glucose-regulating genes including Pdx1, insulin, glucagon, and Ngn3 genes in poly-L-lactic acid and polyvinyl alcohol (PLLA/PVA) 3D scaffold than in the regular 2D culture [133]. The 3D scaffold provides a supporting structure to maintain the cell-cell and cell-matrix interactions. The stem cells cultured in nanofibrous scaffolds generate pancreatic organoids which are morphologically and functionally similar to the mature pancreatic $\beta$-cells [134-136].

The main advantage of using cell sheets is the fabrication techniques that will not disrupt the cell-cell and cell-matrix contact [137]. Usage of cell sheets fabrication techniques such as temperature-responsive culture surface, photoresponsive polymer, and ultrasound irradiation enables the detached cells to maintain their cell surface proteins, cellular junctions, and extracellular matrix [138]. Cell sheets may be developed into an advanced cell delivery method for the treatment of many tissue injuries, including cardiovascular diseases, cutaneous wound healing, and tendon/ligament injuries. The combination of multiple cell sources in the fabrication of cell sheets may mimic the natural state of tissue to allow better grafting of cells and better tissue regeneration.

\section{Stem Cells and Secretome Clinical Trials}

6.1. Stem Cell Clinical Trials. Thus far, many clinical trials using MSCs have been completed, and some of the therapies, e.g., Cupistem ${ }^{\circledR}$, Queencell ${ }^{\circledR}$, Cartistem ${ }^{\circledR}$, Cellgram ${ }^{\circledR}$, Neurorata- $\mathrm{R}^{\circledR}$, Prochymal ${ }^{\circledR}$, Stempeucel ${ }^{\circledR}$, and MesestroCell, have received market authorization in Korea, Canada, India, and Iran [139]. A list of worldwide clinical studies using stem cells in different phases can be found in National Institutes of 
Health Clinical Trials.gov website (https://www.clinicaltrials .gov/) (Table 2).

6.1.1. Pluripotent Stem Cells. There are eight completed clinical trials on ESC transplantation, and seven of them are associated with eye disease and one for ischemic heart disease. The PSC clinical trials mainly focus on eye disease as the tissue is easily accessible for transplantation, and serious adverse events (SAEs) on the eye are less likely to be lifethreatening. Furthermore, PSC transplantation is associated with higher risks of tumor formation. Since the eyeball is a confined space that has few vasculature connections with the rest of the body, the tumor is less likely to metastasize. However, none of the studies listed is presented with results. All these studies are either phase I or phase I/II, indicating that the translational research of PSC therapy is still in the early phase.

6.1.2. Multipotent Stem Cells. There are more completed MSC clinical trials compared to the PSC clinical trials as the cells are safer and have fewer ethical concerns. Many MSC clinical trials have published their results. Generally, MSC therapy is found to be safe and well-tolerated by the patients. In addition, some studies also reported the efficacy of MSC therapy to treat a battery of diseases. MSC therapy has received market authorization in several countries for the treatment of diseases such as Crohn's fistula, cartilage defects, osteoarthritis, major adverse cardiac events, amyotrophic lateral sclerosis, aGvHD, and critical limb ischemia [139]. Very recently, a parallel assigned controlled, nonrandomized phase I clinical trial has been conducted to evaluate the safety of human umbilical cord-derived mesenchymal stem cell (UC-MSC) infusion to treat patients with moderate and severe COVID-19 pulmonary disease [140]. Eighteen hospitalized COVID-19 patients were enrolled on the study, and nine of them received three cycles of intravenous infusion of UC-MSCs $\left(3 \times 10^{7}\right.$ cells/infusion). Twenty-eight days after the first infusion, no UC-MSC infusion associated SAEs were observed except for one patient in the treatment group that required mechanical ventilation compared to four patients in the control group. All patients recovered following the treatment and were discharged. These data showed that intravenous UC-MSC infusion is safe and welltolerated in patients with moderate and severe COVID-19.

6.2. Secretome Clinical Trials. Clinical trials of cell-free therapy are taking the emerging field from basic science to clinical application. Numerous trials are/have been conducted for a huge variety of conditions. While there are reviews that have summarized previous clinical trials pertaining to the use of cell-free therapy, we intend to highlight several clinical studies that are recently published at the time of this writing (Table 3). Unfortunately, to date, the results from many of these clinical trials have yet to be published.

Overall, stem cell therapy has a longer history compared to cell-free therapy. A review on the stem cell clinical trials was published in the year 2011 [156]. One decade has passed since then, and a significant change in the current trend of stem cell clinical trials has been observed, most noticeably, the quantity (Figure 4). In 2011, 123 clinical trials using MSCs were recorded. Although some of the studies are in the combination of phase I/II, the majority are in phase II. The quantity of MSC clinical trials has grown tremendously, circa 25 times since the past decade. Notwithstanding, a total of 152 clinical trials using exosomes have also been recorded in the last 10 years. Although there is a huge surge in the number of clinical trials on MSCs and exosomes, the disease treated has not varied significantly and most of which are chronic diseases and disorders. While it is too hasty to draw a conclusion of the efficacy of cell-based therapy, the early observations of these trial results demonstrated that it is safe and feasible.

However, the clinical applications of MSCs or secretome are not without risks. Several pertaining concerns are promoting the growth of cancerous cells and nonspecific and undesirable differentiation of the transplanted cells at the target tissue. Perhaps, the most relevant risk of stem cell therapy is the malignant transformation of the administered cells. Many researchers have reported genomic instability in MSCs at higher passage $[157,158]$. Thus, genotyping might be relevant to ensure the safety of the cells before transplantation.

\section{Stem Cell vs. Secretome}

7.1. Manufacturing. As a cellular product, the cell source poses the first major challenge to reproducibly manufacture clinically effective stem cells and secretome products. Stem cell manufacturing has been critically reviewed and discussed in the previous publication [159]. The production of stem cells is indeed a quite straightforward process. The stem cells can be grown on a large scale using bioreactors or large cell culture flasks under specific culture conditions [160]. Largescale expansion is crucial to produce enough cells for downstream clinical application. Human platelet lysate (HPL) is often recommended as an alternative to fetal bovine serum (FBS) for good manufacturing practize- (GMP-) compliant stem cell expansion. Generally, stem cells cultured with HPL are smaller in size, display a tighter spindle-shaped morphology, and increased cell growth [161]. In addition, a chemically defined serum-free medium also can be used to replace the serum-based medium to avoid the batch-tobatch variation bothering the serum-based medium.

The manufacturing of clinically effective secretome is not an easy process. Notably, the quality and quantity of secretome are greatly influenced by the cell source and culture condition. Although secretome has been proven to work as effective as stem cells, nevertheless, it does not guarantee that the secretome harvested could work in the same way or as effective as the cultured cells. In vivo, transplanted stem cells produce secretome that could regenerate/repair the tissue or modulate the immune function in response to the signalling from the surrounding tissue. In contrast, this does not happen when the cells are grown in the laboratory. Therefore, it might be necessary to customize the culture condition that mimics the pathophysiological environment to produce clinically effective secretome [162].

When an appropriate cell source of clinically effective secretome is identified, the consistency of the cell source for 


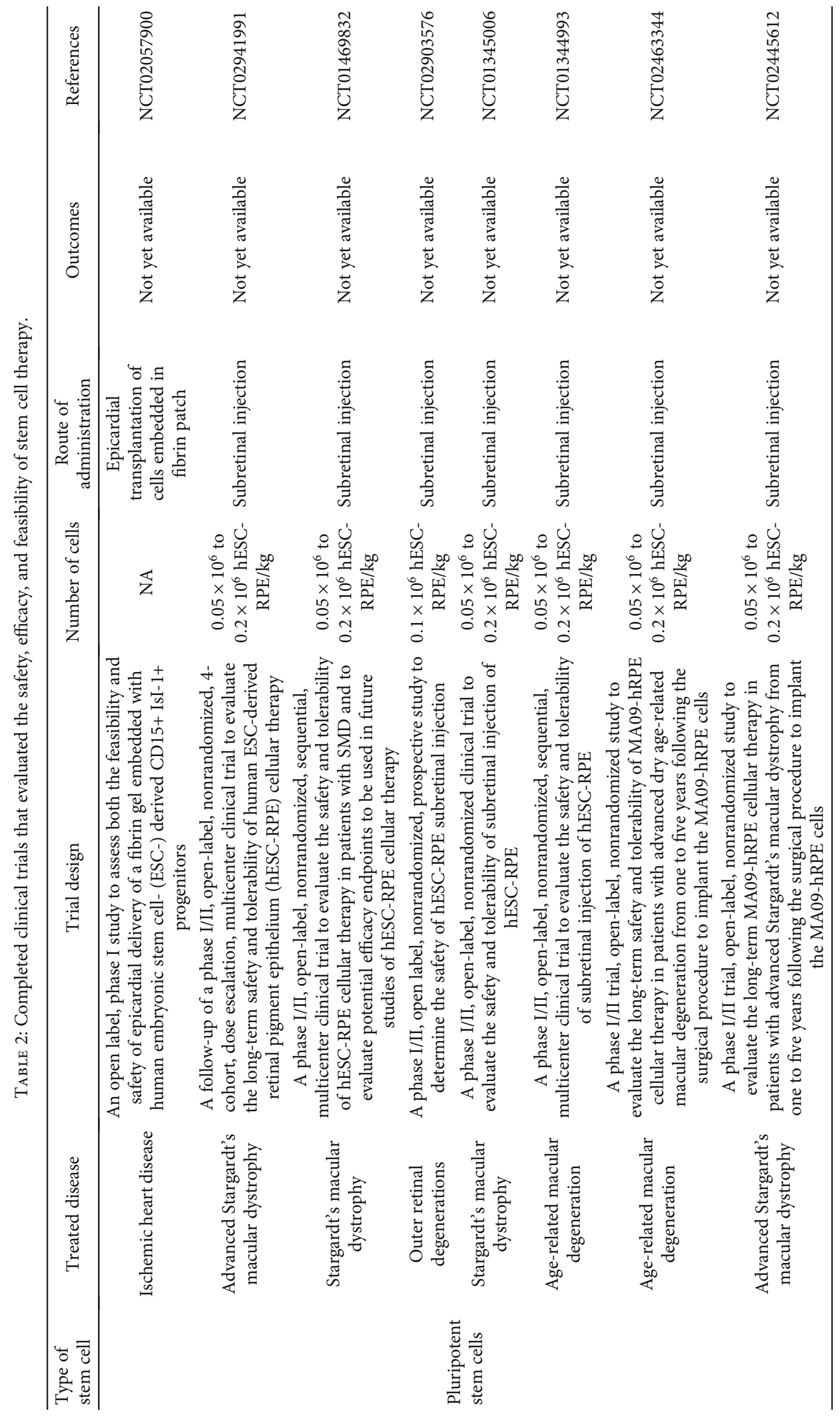




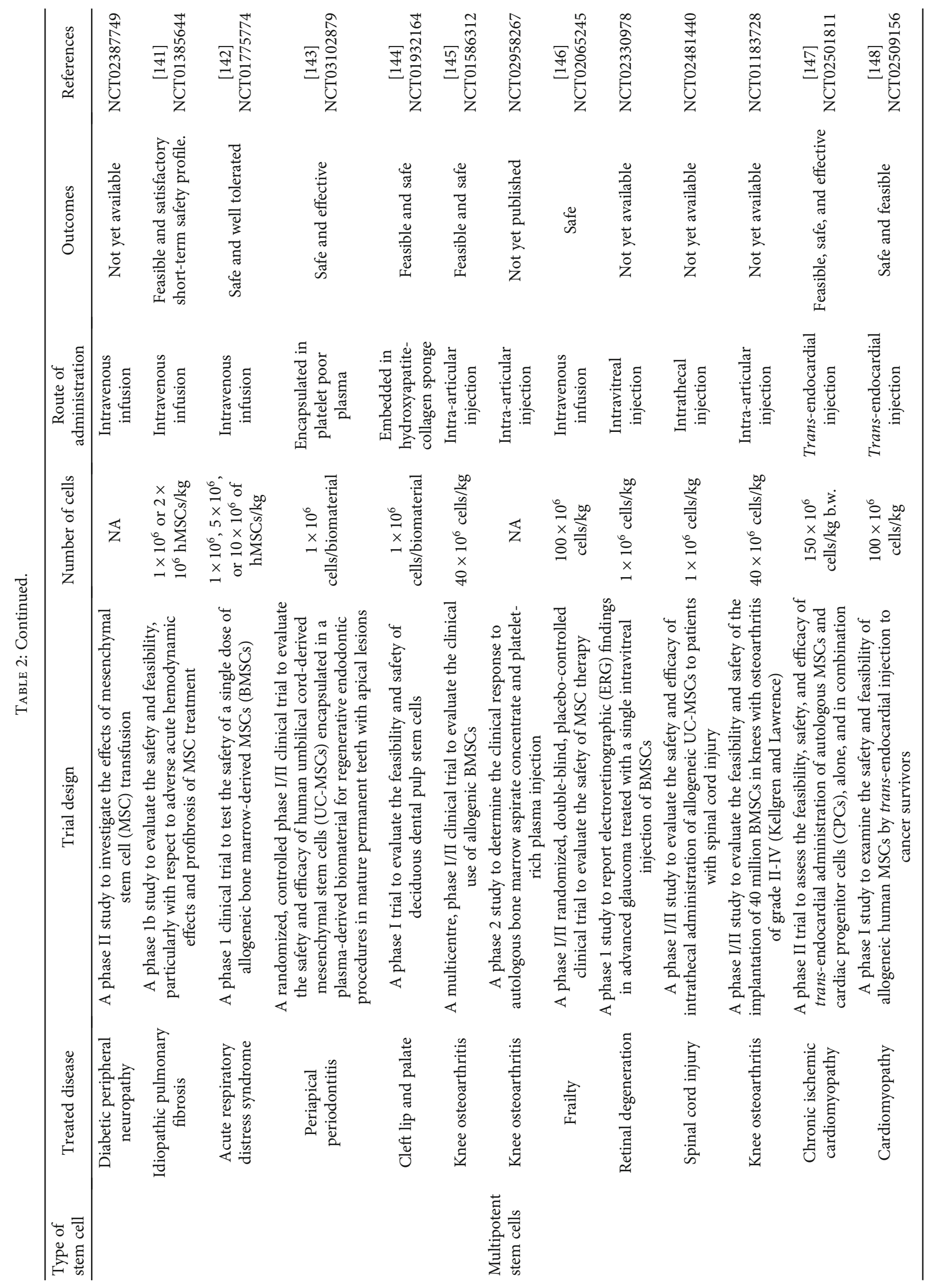




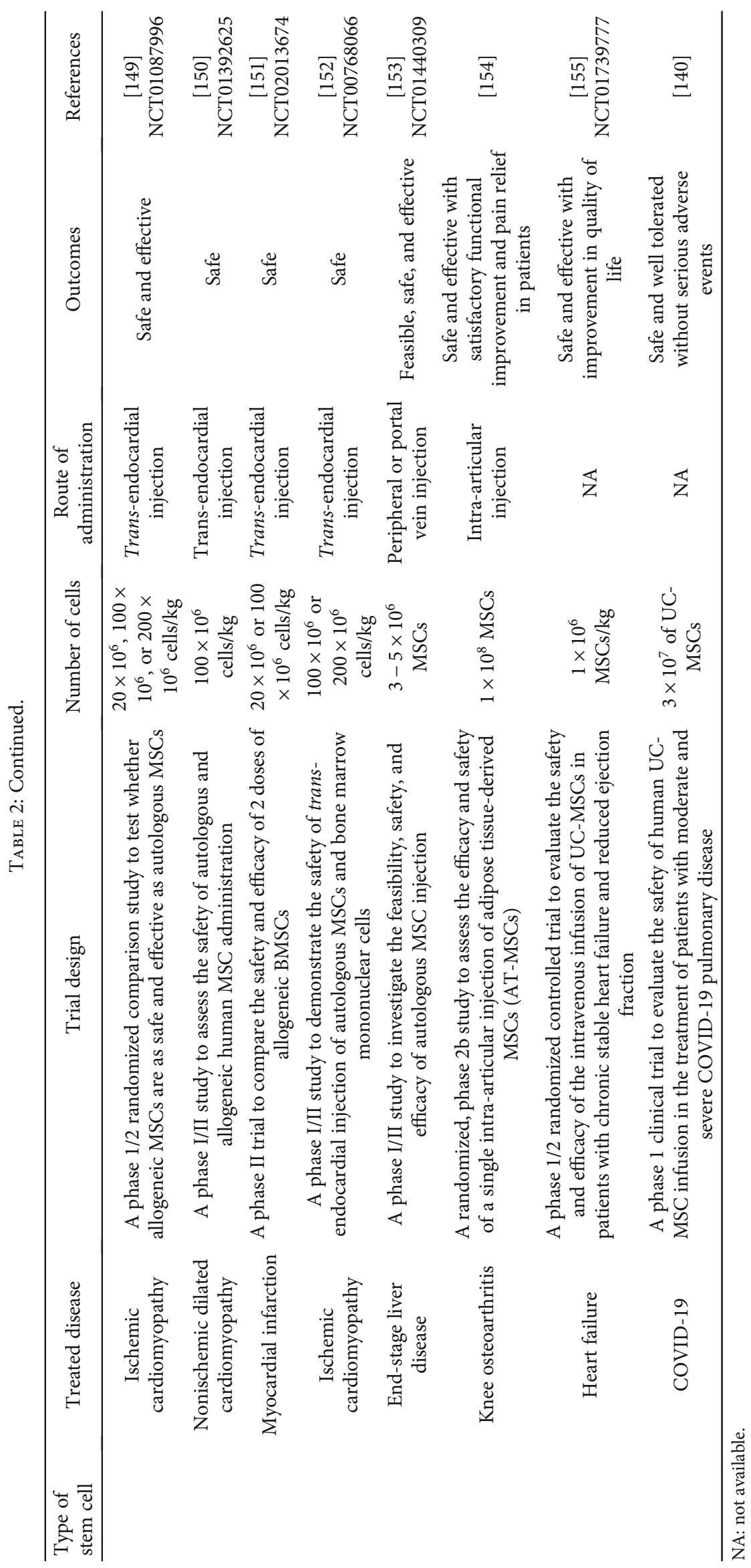


TABLE 3: Cell-free treatment in clinical trials for various diseases.

\begin{tabular}{|c|c|c|c|c|c|}
\hline Target disease & Cell & $\begin{array}{l}\text { Clinical trials } \\
\text { identifier }\end{array}$ & Administration & Dosage & Results \\
\hline COVID-19 & MSC-derived exosomes & NCT04491240 & Inhalation & $\begin{array}{c}0.5-2 \times 10^{10} \\
\text { exosomes }\end{array}$ & $\begin{array}{l}\text { No observable side } \\
\text { effects in } 30 \text { days. } \\
\text { Improvement in overall } \\
\text { treatment is not } \\
\text { insignificant compared } \\
\text { to standard therapy. }\end{array}$ \\
\hline Chronic ulcer & MSC conditioned media & NCT04134676 & Topical & Unknown & Not available \\
\hline Keloid & $\begin{array}{l}\text { Umbilical cord-MSC } \\
\text { conditioned medium }\end{array}$ & NCT04326959 & Intralesional & $1 \mathrm{~mL} / \mathrm{cm}^{3}$ & Not available \\
\hline Knee osteoarthritis & $\begin{array}{l}\text { MSC conditioned } \\
\text { medium }\end{array}$ & NCT04314661 & $\begin{array}{l}\text { Intra-articular } \\
\text { injection }\end{array}$ & $\begin{array}{l}2 \mathrm{~mL} 2 \text { weeks after } \\
5 \times 10^{5} \text { MSC cells }\end{array}$ & Not available \\
\hline $\begin{array}{l}\text { SARS-CoV-2- } \\
\text { associated } \\
\text { pneumonia }\end{array}$ & MSC-derived exosomes & NCT04276987 & Inhalation & $\begin{array}{l}2.0 \times 10^{8} \\
\text { vesicles } / 3 \mathrm{~mL} \\
\text { for } 5 \text { days }\end{array}$ & Not available \\
\hline $\begin{array}{l}\text { Multiple organ failures } \\
\text { after surgical repair of } \\
\text { aortic dissection }\end{array}$ & MSC-derived exosomes & NCT04356300 & Intravenous & $\begin{array}{l}150 \mathrm{mg} \text { exosomes } \\
\text { for } 2 \text { weeks }\end{array}$ & Ongoing \\
\hline Chronic low back pain & $\begin{array}{l}\text { Platelet-rich plasma } \\
\text { with exosomes }\end{array}$ & NCT04849429 & Intrathecal & $2 \mathrm{~mL}$ & Ongoing \\
\hline $\begin{array}{l}\text { Cerebrovascular } \\
\text { disorders }\end{array}$ & MSC-derived exosomes & NCT03384433 & Intravenous & Not available & Ongoing \\
\hline COVID-19 & $\begin{array}{l}\text { MSC conditioned } \\
\text { medium }\end{array}$ & NCT04753476 & Intramuscular & $0.5-1 \mathrm{~mL}$ (3 doses) & Ongoing \\
\hline
\end{tabular}

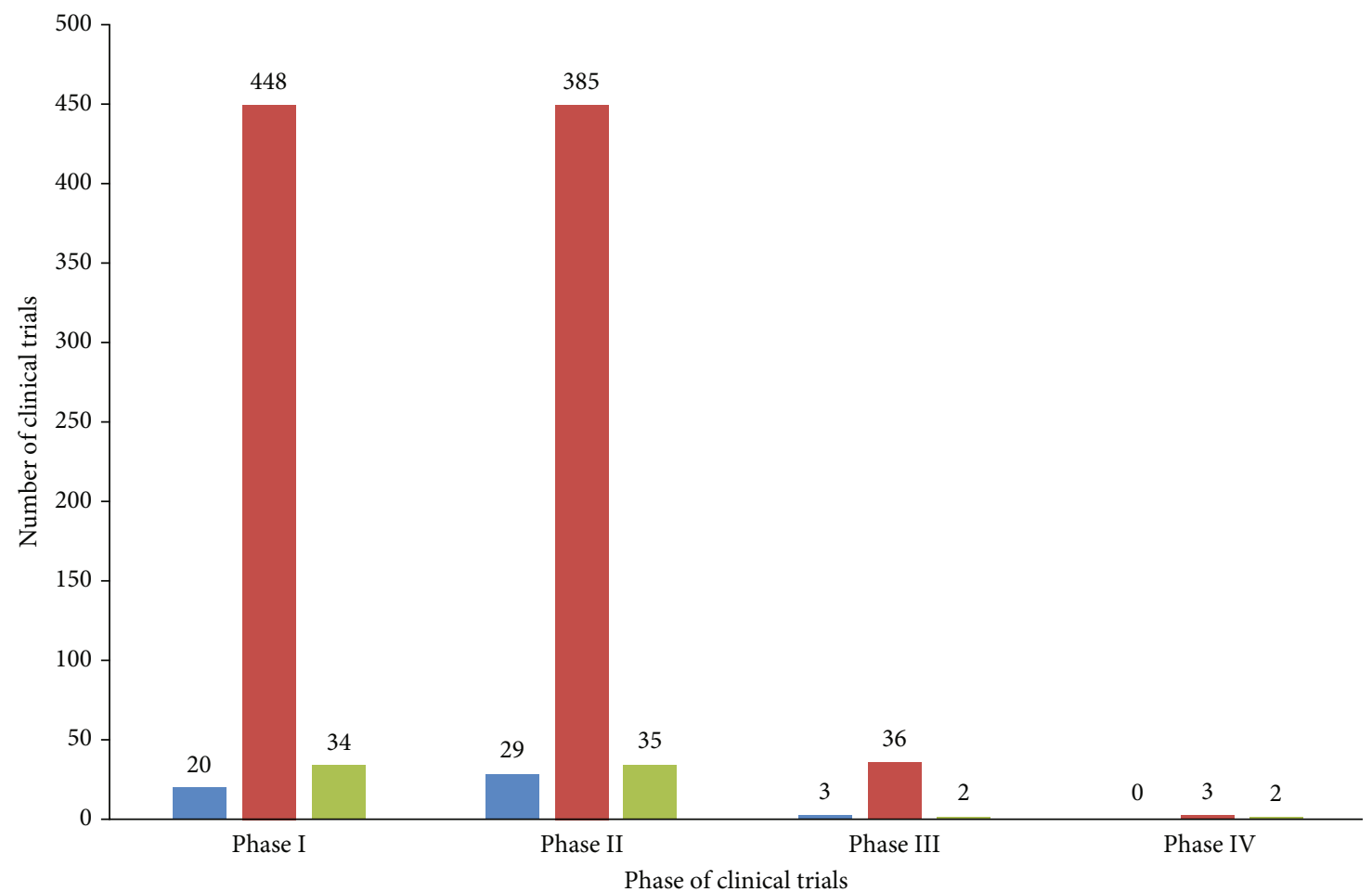

MSC (as of 2011)

MSC (as of 2021)

Exosomes (as of 2021)

Figure 4: Number of mesenchymal stem cell (MSC) and exosome clinical trials between 2011 and 2021 by clinical phase (source: clinicaltrials.gov [accessed 5/5/2021]). 
all subsequent batches of secretome production must be addressed. This could be achieved by pooling the cells from the same tissue source of different healthy donors to produce multiple batches of secretome, mitigating the challenges of biological variation in tissue sources and donors [163]. Due to the finite replication of the primary cells, a more practical approach is to use "immortalized" cell lines or PSC-derived stem cells. Although studies have reported that the regenerative properties of secretome [164] and sEVs [165] harvested from immortalized stem cells are not compromised. Nevertheless, all these must be carefully investigated to ensure that the immortalized cells are stable and continue to produce secretome products that are bioequivalent to those from nonimmortalized parental cells. In addition, secretome enrichment protocols could also be employed to enhance the production of secretome in the laboratory [166]. It should be taken into consideration that the type of media used to harvest secretome may also affect the quality and efficacy of secretome. To avoid interference from HPL, basal media is often employed to harvest the secretome to determine the efficacy of stem cell secretome. Nevertheless, the sudden switch from nutrient-rich to basal media may change the cell's behavior and subsequently modifying the secretome profile. Would the basal media harvested secretome work as effective as the stem cells in the host and whether the secretome harvested from cells cultured in complete growth media might have better clinical efficacy compared to the secretome harvested from basal media are some of the questions that remain to be answered. Based on the abovementioned arguments, the quality of secretome preparation is dependent on the source, culture condition, and secretome enrichment protocol. Therefore, secretome manufactured using different protocols may have different disease-relevant potency.

7.2. Quality Control. Quality control is crucial to ensure the safety and efficacy of cell-based products. Adherence to the GMP regulations assures the identity, strength, quality, and purity of the products. Strict adherence to the quality management system helps to prevent contamination, mix-up, deviation, failure, and error during production [167]. It is important to note that a lot of efforts have been given to establish GMP facilities to produce cellular products for clinical applications [168]. Apart from the GMP facility, guidelines are in place to characterize the stem cells. For instance, MSCs should be characterized according to the guideline recommended by the International Society of Cellular Therapy (ISCT) [169].

The quality control for secretome is way more complex compared to the stem cells. As the secretome is a mixture of EVs and soluble proteins, it is challenging to identify the active components from this mixture and hence, more efforts are required to characterize the secretome. For instance, proteomic analysis is needed to identify the type of proteins and their concentration in the preparation $[96,170]$. For EVs, particularly small EVs (sEVs), it needs to be characterized according to the guidelines published by the International Society of Extracellular Vesicles (ISEV). The identification of size and number would require either zetasizer or nanoparticle tracking analysis (NTA). Notably, quantifiable met- rics defining the identity of sEV preparations should reflect the cellular origin of the sEVs in preparation, the presence of lipid membrane vesicles, and the degree of physical and biochemical integrity of the vesicles. The combination of these metrics could quantify the identity of sEVs and facilitate stratification and comparison of different secretome preparations [77, 171]. As EVs contain miRNAs, the molecular technique is also required to characterize the miRNA profile $[172,173]$.

7.3. Cost of Production and Treatment. There is an argument whether the cost of production and treatment is lower in secretome therapy in comparison to stem cell therapy. For stem cell therapy, the number of stem cells that could be isolated from patients/donors is low; therefore, the harvested cells are usually expanded in the laboratory to attain enough cells for clinical applications. The process can take weeks to months. During the cell expansion, media change is typically done every 3-4 days. The high volume of spent media means to be discarded is a potential source of secretome that can be used clinically after proper processing. The preparation of cell-free therapies from the spent media can greatly reduce the cost of production. However, need to bear in mind that the secretome or exosomes collected form the spent media could have different biological components when the cells are cultured in different conditions. Thus, it is imperative to determine safety and efficacy as well as to characterize the secretome or exosomes secreted by cells cultured in different conditions. In another words, not all spent media can be processed to produce safe and effective secretome and exosomes.

Furthermore, as the secretome cannot self-replicate and have a short half-life in vivo, thus, the secretome might need to be given more frequently to exert its therapeutic effect. In contrast, stem cells can self-renew and survive in the body for a longer period. Stem cells can respond to the signaling molecules released by the injured cells by secreting the appropriate paracrine factors to stimulate tissue regeneration. On the other hand, the contents of secretome are already defined in vitro. Thus, preconditioning of the cells at the culture condition that mimic the disease pathophysiological condition might be needed to produce clinically relevant secretome. The used of specific instruments or biochemicals to replicate the disease pathophysiological condition in vitro will incur extra costs. Finally, the cost of secretome production is still likely to be higher than the cells as it requires extra concentration and purification steps [174].

7.4. Advantages and Disadvantages. The use of stem cells as regenerative medicine for various diseases has been progressing well since the past decade. However, the type of stem cell suitable for different diseases is still under vigorous debate since each stem cell subtype possesses its advantages and limitations. For instance, ESCs can differentiate into various types of tissue but its limitations, i.e., ethical dilemma, genetic instability, and teratocarcinoma, might overweight the benefits [175]. MSCs show several superior properties for therapeutic use compared to other types of stem cells, including easy to harvest and expand, both autologous and allogeneic 
cells can be used with minimal risk of rejection, free from ethical issues and have limited replicative lifespan, and hence have lower risks of malignant formation. However, MSCs are only capable to differentiate into certain lineages thus limiting their usage to only certain diseases [176]. Notably, stem cells could be differentiated into specific tissue as cell replacement therapy $[177,178]$. This is the main advantage of stem cells over secretome. Another prominent property of stem cells is their ability to migrate to the site of injury (homing effect). Surprisingly, sEVs also possessed the homing ability. Studies showed that MSC-EVs were mainly accumulated in the inflamed kidneys [179] and injured brains [180, 181] in the acute kidney injury model and intracerebral haemorrhage models, respectively. The accumulation of systemically injected sEVs in the intracerebral hemorrhage model also showed that sEVs can cross the blood-brain barrier (BBB). Research also has indicated that stem cells could cross BBB. MSCs integrated into the endothelium through the adhesion molecules VCAM-1/VLA-4 and $\beta 1$ integrin. After crossing the endothelial barrier, MSCs invade the host tissue via plasmic podia [182]. MSCs were also found to cross BBB through paracellular pathways that are normally inhibited by the presence of tight junctions [183]. These showed that both stem cells and secretome could be intravenously injected and reach the brain. Nevertheless, the bioavailability of these two subjects in the brain remains to be elucidated.

Accumulating evidence suggests that secretome possesses many advantages over stem cell transplantation. Cell degeneration or senescence in the host after transplantation is not a concern for secretome therapy. It was also reported that secretome has lower cell surface proteins compared to stem cells, which makes allogeneic secretome safer than allogeneic stem cells because of the lower risk of immunogenicity [184]. Irreplicable property and absence of DNAs in secretome greatly reduce the risk of DNA mutation and tumor formation in the host. The use of secretome also reduces the possibility of vascular obstruction compared to larger stem cells. The bioactive components of secretome can be easily modulated by culturing the cells in different conditions. Secretome is also easier to store compared to stem cells, i.e., stem cells need to be stored in liquid nitrogen to maintain their viability while secretome can be stored in $-20^{\circ} \mathrm{C}$. Finally, the requirement to evaluate the safety and dosage of secretome is less stringent in comparison to the stem cells, making the journey to the clinical setting smoother and faster. This is because stem cells are living cells, and the fate of the transplanted cells is more difficult to predict. Table 4 and Figure 5 summarize the comparison between stem cells and secretome from the perspective of manufacturing, quality control, cost of production, and treatment, as well as their advantages and disadvantages in clinical applications.

\section{Future Perspective}

Currently, cell-based therapies face two great challenges; how to anticipate decreased cell viability and biological functions during in vitro culture and how to prolong survival of transplanted cells. Consequently, several strategies can be envisaged to increase survival, immunomodulatory potential, and regenerative functions of cell-based therapy. Preconditioning, genetic modification, and tissue engineering are the dominant strategies. Furthermore, combinatorial approaches using nanotechnology could also improve the therapeutic performance of stem cells and secretome.

\subsection{Stem Cells}

8.1.1. Genetic Modification. The combination of stem cell biology and genetic engineering has great potential in regenerative medicine. Through genetic modification, the researcher could induce or determine the cell's specific differentiation pathway after injection or enhance the adhesion potential of the stem cell to specific target. After transplantation, the fate of MSCs would be stochastically determined based on the microenvironment and biochemical stimulation of the host body; therefore, not all transplanted cells would contribute to the regeneration of damaged organs. As recently demonstrated in mice, transplanted MSCs could differentiate into osteoblasts in the heart [185]. Although cell differentiation can be achieved using the biochemical or biophysical stimulus in vitro, however, reverse differentiation may occur after transplantation or withdrawal of stimulants [186]. Therefore, genetic modification of the transplanted stem cells would be the key to achieve a directed and irreversible differentiation into the desired lineage. Several studies have been conducted on the therapeutic applicability of genetically modified MSCs in animal models of diabetes, myeloma bone disease, GvHD, and myocardial infarction. Table 5 summarizes the modifiers, cell source, genetic engineering method, and applications from various studies.

In addition to the ability to differentiate, MSCs can be genetically engineered to home to the target tissue. For example, MSCs transduced with CXCR4 demonstrated higher homing in the mice model of myocardial infarction after intravenous administration [110, 235]. The overexpression of CXCR4 facilitated MSC aggregation and etching of collagenous tissue of the infarcted area [236]. Such strategies will help in the development of noninvasive cell therapies, since the route of administration is also important to avoid the formation of heterotopic tissue, especially in the case of genetically modified MSCs. On the other hand, poor cell survival after transplantation is a yet to resolved hurdle in MSCbased therapies. Studies show that genetic modification of MSCs with hypoxia-regulated heme oxygenase-1 (HO-1), Akt1, and Bcl-2 increased cell survival after transplantation in animal models by inhibiting cell apoptosis [236-238]. Thus, these strategies might be the possible solutions to increase the survival of MSCs after transplantation.

8.1.2. Tissue Engineering Using MSCs. Another area of regenerative medicine is to combine cells and scaffolds to create a $3 \mathrm{D}$ implant. Tissue engineering seeks to recreate the in vivo environment to promote the development of tissues needed for transplantation. Various approaches have been studied, including protein-impregnated scaffolds [239], gene vectorincorporated templates [240], and cell-scaffold combinations (Table 6). Scaffolding alone has been shown to help repair certain types of damage [239]. However, incorporating MSCs 
TABLE 4: Comparison between stem cell and secretome.

\begin{tabular}{|c|c|c|}
\hline Aspect & Stem cell & Secretome \\
\hline Manufacturing & $\begin{array}{l}\text { (i) General culture condition is normally used but special } \\
\text { culture condition might be needed to produce specific } \\
\text { cells (e.g., chondrogenic media to produce } \\
\text { chondrogenic-differentiated MSCs) } \\
\text { (ii) The consistency of the cell source has to be maintained } \\
\text { for allogeneic stem cells } \\
\text { (iii) May contain elements of external sources (FBS, HPL) } \\
\text { (iv) Require a large number of cells for clinical applications }\end{array}$ & $\begin{array}{l}\text { (i) General culture condition can be used but special culture } \\
\text { condition mimicking the pathophysiological condition } \\
\text { of the target diseases might be needed to produce the } \\
\text { "bioequivalent" secretome } \\
\text { (ii) The consistency of the cell source has to be maintained } \\
\text { (iii) Enrichment protocol might be needed to enhance the } \\
\text { production of secretome } \\
\text { (i) Secretome may contain elements of external sources } \\
\text { (FBS, HPL) } \\
\text { (ii) High volume of media is collected, and it needs to be } \\
\text { processed and concentrated for clinical applications }\end{array}$ \\
\hline $\begin{array}{l}\text { Quality } \\
\text { control }\end{array}$ & $\begin{array}{l}\text { (i) Stem cell markers are well established } \\
\text { (ii) The characterization techniques are well established } \\
\text { (iii) Specific functionality assay is needed to determine the } \\
\text { efficacy }\end{array}$ & $\begin{array}{l}\text { (i) The characterization is complex since secretome contain } \\
\text { many elements such as growth factors, cytokines, and } \\
\text { extracellular vesicles } \\
\text { (ii) Specific functionality assay is needed to determine its } \\
\text { efficacy }\end{array}$ \\
\hline $\begin{array}{l}\text { Cost of } \\
\text { production } \\
\text { and treatment }\end{array}$ & $\begin{array}{l}\text { (i) Cost can be reduced via large-scale expansion of } \\
\text { allogeneic stem cells } \\
\text { (ii) Treatment dose is easier to be justified by number of cells }\end{array}$ & $\begin{array}{l}\text { (i) Repetitive collection of secretome from spent culture } \\
\text { media can greatly reduce the cost of production } \\
\text { (ii) Extra cost is needed for downstream processing of } \\
\text { secretome (concentration and purification) } \\
\text { (iii) Treatment dose is vague (protein amount vs number of } \\
\text { particles) } \\
\text { (iv) It is unsure which component(s) of the secretome are } \\
\text { exerting therapeutic effects }\end{array}$ \\
\hline
\end{tabular}

(i) Stem cells can be differentiated into specific lineages to improve the therapeutic efficacy and treat different diseases

(ii) Mesenchymal stem cells are easy to isolate and expand, have low immunogenicity (both autologous and allogeneic cells can be used clinically), free from ethical issues, and have limited replicative lifespan, hence safe from malignant formation

Advantages (iii) Can be reprogrammed into pluripotent stem cells (PSCs)

(iv) Can cross blood-brain barrier (BBB)

(v) Can migrate and home to the target tissue in response to the signal release by the injured cells

(vi) Living cells can exert the therapeutic effects for a longer period. Thus, less frequency of administration is needed (e.g., once in every 6 months)

(i) Higher risk of mutation and carcinogenesis (especially the PSCs)

(ii) Ethical issue (embryonic stem cells)

(iii) Might illicit host immune response to reject the transplanted cells (especially the allogeneic stem cells)

Disadvantages transplantation

(iv) Cell degeneration or senescence in the host after

(v) Potential vascular obstruction

(vi) More stringent storage condition to maintain the cell viability

(vii) More optimization is needed to improve the safety and efficacy (e.g., optimum dosage and route of administration) (i) The therapeutic components of the secretome could be customized by modifying the culture condition (preconditioning)

(ii) Can cross BBB

(iii) Can circulate and home to the target tissue

(iv) Low risk of mutation, carcinogenesis, and immunogenic as they are not living cells

(v) Lower risk of vascular obstruction as they are smaller in size compared to stem cells

(vi) Easier to store

(vii) Cell degeneration or senescence in the host after transplantation is not a concern

(i) Cannot be used as cell-replacement therapy and relying on the proliferation of host cells for tissue regeneration

(ii) Lack of understanding on its mechanism of action

(iii) Lack of long-term safety data

(iv) Lack of standardization

(v) Short half-life in the body. Thus, might need more frequent administration

(vi) Difficult to purify the specific therapeutic components (e.g., exosomes). Thus, the secretome products are highly heterogeneous into the scaffold improves the in situ repair process by acting as the precursors and stimulators [241].

Over the decades, much effort has been devoted to study the physical and chemical properties of various biomaterials, as these properties affect the differentiation pathway and adhesion capacity of MSCs. For example, the elasticity of a polyacrylamide matrix seeded with MSCs determines their differentiation pathway into neuronal, muscle, or bone lineage based on crosslink density [247]. Furthermore, studies indicated that the presence of carboxyl or hydroxyl groups 


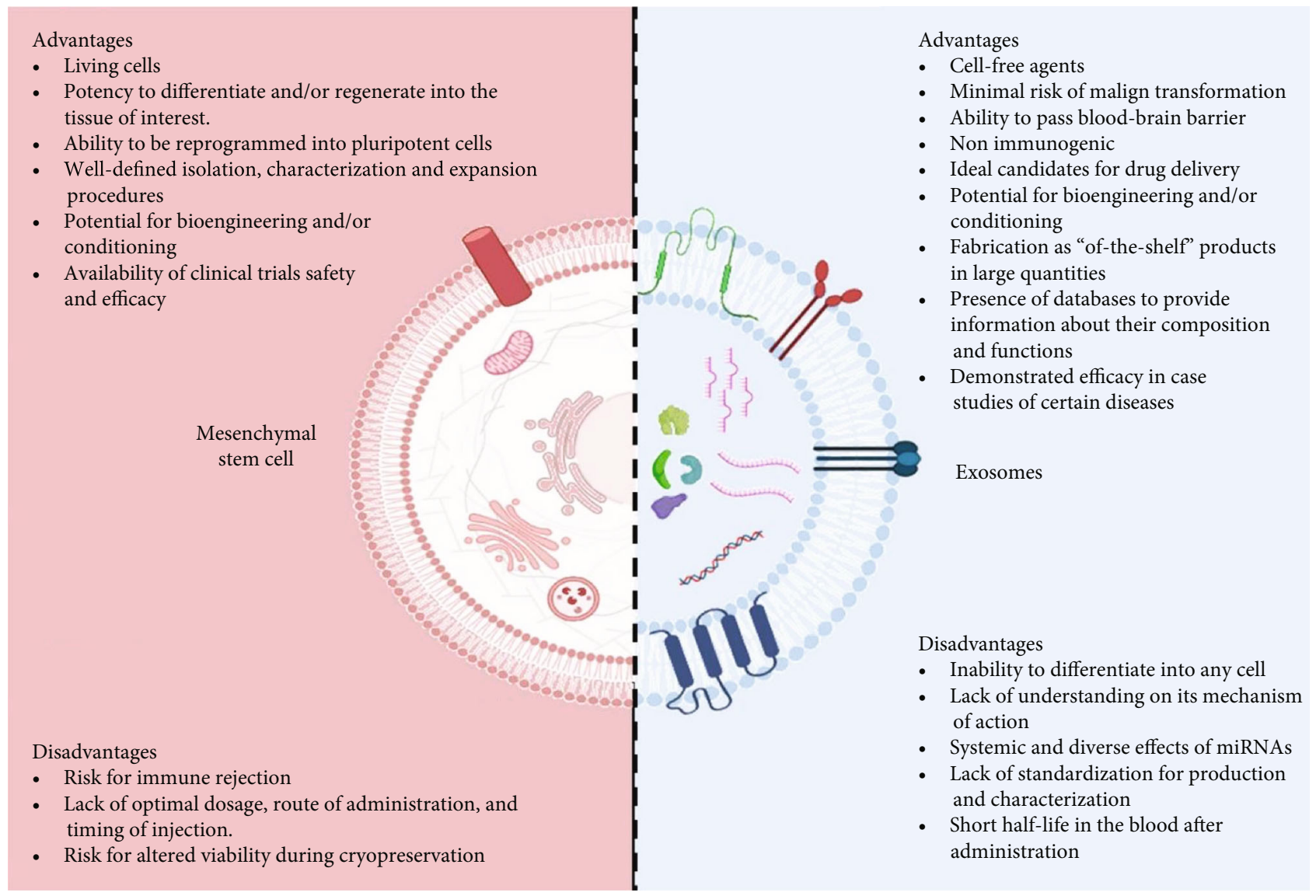

Figure 5: Advantages and disadvantages of MSCs and MSC-derived exosomes (created with BioRender.com).

on the scaffold surface prioritizes chondrogenic differentiation, while amino and sulfhydryl groups promote bone formation [248]. In addition to biometric properties, graft angiogenesis is another important factor in ensuring cell survival and therapeutic efficiency. The host's blood vessels can invade the transplant, but the process is very slow, and it takes weeks to vascularize just a few millimeters. Therefore, researchers incorporate angiogenesis-promoting factors such as endothelial progenitor cells (EPCs) and VEGF to hasten graft angiogenesis [249]. Unfortunately, no perfusion was observed upon implantation [250]. Currently, there are no established angiogenesis strategies available to support transplantation of large tissue due to delayed angiogenesis which resulted in cell apoptosis and necrosis. The approaches mentioned above only could increase the likelihood of angiogenesis.

\subsection{Exosomes}

8.2.1. Preconditioning. Both $3 \mathrm{D}$ culturing and pretreatment of MSCs with cytokines, hypoxia, or chemicals are reliable methods to increase exosome secretion (Figure 6) [251]. In addition, MSC gene and cell surface modifications may be used to improve the therapeutic effect of exosomes.

(1) Increasing Exosome Production. Increasing the secretion of exosomes is an important but unmet process. Studies have shown that $3 \mathrm{D}$ culturing methods such as bioreactors and microcarriers could significantly increase the production of exosomes by cultured MSCs [252]. Generally, MSCs are processed on $2 \mathrm{D}$ surfaces in plastic dishes that do not reflect the physiological niches of MSCs. Therefore, the use of a 3D porous scaffold structure, such as beads, microfiber, or any other type of carrier is an attractive method to increase exosome production. One study showed that antifungal agents, i.e., imidazole and nitrefazole, significantly increase the production of exosomes in prostate cancer cells [253]. In this case, nitreprazole increased the level of the protein Rab27a, which regulates MVB exocytosis. Other chemicals, such as azole and pentetrazole, have also been shown to activate exosome biogenesis-related molecules, i.e., Alix and NSmas2. The techniques may be employed to increase the production of exosomes from MSCs by modulating the biogenesis and release of exosomes [253]. On the other hand, gene editing is another effective way to increase the production of exosomes. There are several important genes, such as phospholipase D2, that are important for the biosynthesis and secretion of exosomes, and the overexpression or dysfunction of these genes promotes exosome secretion. For example, the overexpression of phospholipase D2 led to a twofold increase in the number of secreted exosomes [254].

(2) Hypoxia Preconditioning. Hypoxia culture is commonly used to prime MSCs. Several studies found that exosomes 
TABLE 5: Genetic modifications in human MSCs and the disease models tested.

\begin{tabular}{|c|c|c|c|c|}
\hline Factor overexpressed & MSC source & Method & Disease & Reference \\
\hline Akt & Human umbilical cord & Adenovirus & Acute myocardial infarction & {$[187]$} \\
\hline Angiotensin II type 2 receptor & Human bone marrow & Lentivirus & LPS-induced acute lung injury & {$[188]$} \\
\hline Arginine decarboxylase & Human adipose tissue & Retrovirus & Spinal cord injury & [189] \\
\hline Basic fibroblast growth factor (bFGF) & Human bone marrow & Lentivirus & Angiogenesis & {$[190]$} \\
\hline \multirow[t]{2}{*}{ Brain-derived neurotrophic factor (BDNF) } & $\begin{array}{l}\text { Human umbilical cord } \\
\text { blood }\end{array}$ & $\begin{array}{c}\text { Plasmid } \\
\text { transfection }\end{array}$ & Neurological injury and disease & [191] \\
\hline & Human bone marrow & Lentivirus & Neuronal degeneration & {$[192]$} \\
\hline C-C chemokine receptor type 2 (CCR2) & Human bone marrow & Lentivirus & Ischemic stroke & [193] \\
\hline CXC chemokine receptor 4 (CXCR4) & Human umbilical cord & Lentivirus & Radiation- induced lung injury & [194] \\
\hline $\begin{array}{l}\text { Cytosine deaminase (CD) and herpes } \\
\text { simplex virus thymidine kinase (HSV-tk) }\end{array}$ & $\begin{array}{l}\text { Human umbilical cord } \\
\text { blood }\end{array}$ & Lentivirus & Ovarian cancer & {$[195]$} \\
\hline Ephrin-B2 & Human bone marrow & $\begin{array}{l}\text { Plasmid } \\
\text { transfection }\end{array}$ & Ischemic tissues & [196] \\
\hline Forkhead box protein (Foxa2) & Human adipose tissue & $\begin{array}{c}\text { Plasmid } \\
\text { transfection }\end{array}$ & Acute liver injury & [197] \\
\hline \multirow{2}{*}{ Glial-derived neurotrophic factor (GDNF) } & Human adipose & Lentivirus & Renal interstitial fibrosis & [198] \\
\hline & Human bone marrow & Adenovirus & Nephrotoxic serum nephritis & [199] \\
\hline $\begin{array}{l}\text { Glucocorticoid-induced tumour necrosis } \\
\text { factor-related receptor (GITR) }\end{array}$ & Human bone marrow & $\begin{array}{c}\text { Plasmid } \\
\text { transfection }\end{array}$ & Small cell lung cancer & {$[200]$} \\
\hline Granulocyte chemotactic protein-2 (GCP-2) & Human adipose tissue & Lentivirus & Myocardial infarction & {$[201]$} \\
\hline Heme oxygenase-1 (HO-1) & $\begin{array}{l}\text { Human embryonic stem } \\
\text { cell }\end{array}$ & Lentivirus & Myocardial infarction & [202] \\
\hline \multirow{7}{*}{ Hepatocyte growth factor (HGF) } & Human bone marrow & Retrovirus & Bladder outlet obstruction & {$[203]$} \\
\hline & Human umbilical cord & Lentivirus & Myocardial infarction & {$[204]$} \\
\hline & Human bone marrow & Adenovirus & Liver fibrosis & {$[205]$} \\
\hline & Human umbilical cord & Adenovirus & Injured sinonasal mucosa & {$[206]$} \\
\hline & Human umbilical cord & Adenovirus & Parkinson's disease & {$[207]$} \\
\hline & $\begin{array}{l}\text { Human umbilical cord } \\
\text { blood }\end{array}$ & $\begin{array}{l}\text { Plasmid } \\
\text { transfection }\end{array}$ & Liver fibrosis & {$[208]$} \\
\hline & Human bone marrow & Lentivirus & Spinal cord injury & [209] \\
\hline Hepatocyte nuclear factor $4 \mathrm{a}(\mathrm{HNF} 4 \mathrm{a})$ & Human umbilical cord & Lentivirus & Hepatocellular carcinogenesis & {$[210]$} \\
\hline Human N-cadherin & $\begin{array}{l}\text { Human umbilical cord } \\
\text { blood }\end{array}$ & Lentivirus & Myocardial infarction & [211] \\
\hline Hypoxia inducible factor-1a (HIF-1a) & Human bone marrow & Lentivirus & Angiogenesis & {$[212]$} \\
\hline IL-4 & Human adipose tissue & Lentivirus & Multiple sclerosis & {$[213]$} \\
\hline \multirow[t]{2}{*}{ IL-10 } & Human amniotic fluid & $\begin{array}{l}\text { Human amniotic } \\
\text { fluid }\end{array}$ & Liver fibrosis & {$[214]$} \\
\hline & Human bone marrow & AAV & Acute ischemic stroke & {$[215]$} \\
\hline Leptin & Human bone marrow & Lentivirus & Myocardial infarction & [216] \\
\hline $\begin{array}{l}\text { LIM-homeobox transcription factor islet-1 } \\
\text { (ISL1) }\end{array}$ & Human bone marrow & Lentivirus & Myocardial infarction & {$[217]$} \\
\hline $\operatorname{miR}-101-3 p$ & Human bone marrow & Lentivirus & Oral cancer & {$[217]$} \\
\hline $\operatorname{miR}-16-5 p$ & Human bone marrow & $\begin{array}{l}\text { Plasmid } \\
\text { transfection }\end{array}$ & Colorectal cancer & [218] \\
\hline miR-199a & Human bone marrow & $\begin{array}{l}\text { Plasmid } \\
\text { transfection }\end{array}$ & Glioma & {$[218]$} \\
\hline miR-199a-3p & Human bone marrow & $\begin{array}{l}\text { miRNA } \\
\text { transfection }\end{array}$ & $\begin{array}{l}\text { Renal ischemia/reperfusion } \\
\text { injury }\end{array}$ & [219] \\
\hline miR-let-7d or miR-154 & Human bone marrow & Lentivirus & Lung injury & {$[220]$} \\
\hline miRNA-181 & $\begin{array}{l}\text { Human umbilical cord } \\
\text { blood }\end{array}$ & Lentivirus & $\begin{array}{c}\text { Myocardial ischemia-reperfusion } \\
\text { injury }\end{array}$ & {$[221]$} \\
\hline
\end{tabular}


TABLe 5: Continued.

\begin{tabular}{|c|c|c|c|c|}
\hline Factor overexpressed & MSC source & Method & Disease & Reference \\
\hline Neuregulin 1 (NRG1) & Human adipose tissue & Adenovirus & Cerebral ischemia & {$[222]$} \\
\hline $\begin{array}{l}\text { Nuclear factor (erythroid-derived 2)-like } 2 \\
\text { (Nrf2) }\end{array}$ & Human amniotic fluid & Lentivirus & Acute lung injury & [194] \\
\hline Oct 4 and Sox 2 & Human adipose tissue & $\begin{array}{c}\text { Plasmid } \\
\text { transfection }\end{array}$ & Liver injury & [223] \\
\hline PARKIN & Human Wharton's jelly & $\begin{array}{c}\text { Plasmid } \\
\text { transfection }\end{array}$ & Parkinson's disease & {$[224]$} \\
\hline Pigment epithelial-derived factor (PEDF) & Human bone marrow & Lentivirus & Hepatocellular carcinoma & [225] \\
\hline SRC3-specific short hairpin RNA (sh-SRC3) & Human bone marrow & Lentivirus & Multiple myeloma & {$[226]$} \\
\hline \multirow[b]{2}{*}{ sST2 } & Human adipose tissue & Lentivirus & Occupational asthma & {$[227]$} \\
\hline & Human adipose tissue & Lentivirus & $\begin{array}{l}\text { Endotoxin-induced acute lung } \\
\text { injury }\end{array}$ & [228] \\
\hline Thioredoxin-1 (Trx-1) & Human umbilical cord & Adenovirus & Acute radiation injury & [229] \\
\hline $\begin{array}{l}\text { Tissue matrix metalloproteinase inhibitor } 2 \\
\text { (TIMP2) }\end{array}$ & Human umbilical cord & Lentivirus & Myocardial infarction & {$[230]$} \\
\hline \multirow{3}{*}{$\begin{array}{l}\text { TNF-related apoptosis-inducing ligand } \\
\text { (TRAIL) }\end{array}$} & Human bone marrow & Lentivirus & Non-small-cell lung cancer & {$[231]$} \\
\hline & Human adipose tissue & $\begin{array}{l}\text { Plasmid } \\
\text { transfection }\end{array}$ & Non-small-cell lung cancer & {$[232]$} \\
\hline & Human adipose tissue & Lentivirus & Glioblastoma multiforme & [233] \\
\hline Transforming growth factor b1 (TGF-b1) & Human bone marrow & Lentivirus & Angiogenesis & [190] \\
\hline Vascular endothelial growth factor (VEGF) & Human bone marrow & Lentivirus & Peripheral nerve injury & [234] \\
\hline
\end{tabular}

TABLE 6: Tissue engineering therapies using MSCs.

\begin{tabular}{|c|c|c|c|c|c|}
\hline Disease & Study organism & Cell & Scaffold & Outcome & Reference \\
\hline Osteochondral defect & Rabbit & Autologous MSCs & $\begin{array}{c}\text { Injectable } \\
\text { synthetic ECM }\end{array}$ & $\begin{array}{l}\text { Cartilage filled the } \\
\text { full-thickness defect }\end{array}$ & {$[242]$} \\
\hline Spinal cord injury & Rat & Autologous MSCs & Hydrogels & $\begin{array}{l}\text { Enhanced ingrowth of } \\
\text { axons in the lesion and } \\
\text { improvement in function }\end{array}$ & [243] \\
\hline Critical size bone defect & Mouse & OSX-modified murine MSCs & Collagen sponge & Enhanced bone formation & {$[244]$} \\
\hline Tendon defect & Rat & $\begin{array}{l}\text { C3H10T1/2 cells stably } \\
\text { transfected with BMP-2 and } \\
\text { active Smad } 8 \text { variant }\end{array}$ & Collagen sponge & Tendon regeneration & {$[245]$} \\
\hline Articular cartilage defect & Rabbit & $\begin{array}{c}\text { Autologous MSCs modified } \\
\text { with TGF-1 }\end{array}$ & Chitosan scaffold & $\begin{array}{l}\text { Enhanced repair; defect } \\
\text { filled with hyaline cartilage }\end{array}$ & {$[246]$} \\
\hline
\end{tabular}

derived from MSCs cultured in hypoxic condition showed greater angiogenic potential compared to exosomes secreted by MSCs cultured in normoxic condition [255]. The exosomes secreted by hypoxia primed MSCs were uptaken more effectively by the target cells compared to exosomes derived from MSCs cultured in normoxic condition. The uptaken exosomes promoted the VEGF expression and protein kinase A signaling pathway activation in the target cells, which resulted in improved angiogenesis [256, 257]. However, the reason for these phenomena is still unclear, and how different culture conditions influence the uptake of exosomes needs to be further investigated.

(3) Chemical Preconditioning. In contrast to hypoxic priming, the effects and mechanisms of biomolecule priming in exosomes are better studied. Various studies have compared the therapeutic effect between lipopolysaccharides (LPS) preconditioned and unconditioned exosomes. LPS conditioned exosome showed higher regeneration potential for liver disease preclinically by reducing the expression of IL6 and TNF- $\beta$ [258] and upregulated the expression of THP-1, which in turn stimulate the synthesis of more antiinflammatory cytokines and contributed to the polarization of M2 macrophages [259]. A recent study has also shown that macrophages cultivated with exosomes from LPSprimed MSCs expressed higher levels of STAT3 gene, secretion of cytokines (IL-10 and IL-15), and growth factors (FLT-3 L) which play vital roles in cell regeneration and antiapoptosis [260]. Several other molecules have been tested as preconditioners, including thrombin to improve fibroblast proliferation, enhance anti-inflammatory effects, accelerate wound healing [176] and melatonin to increase BCL2, 


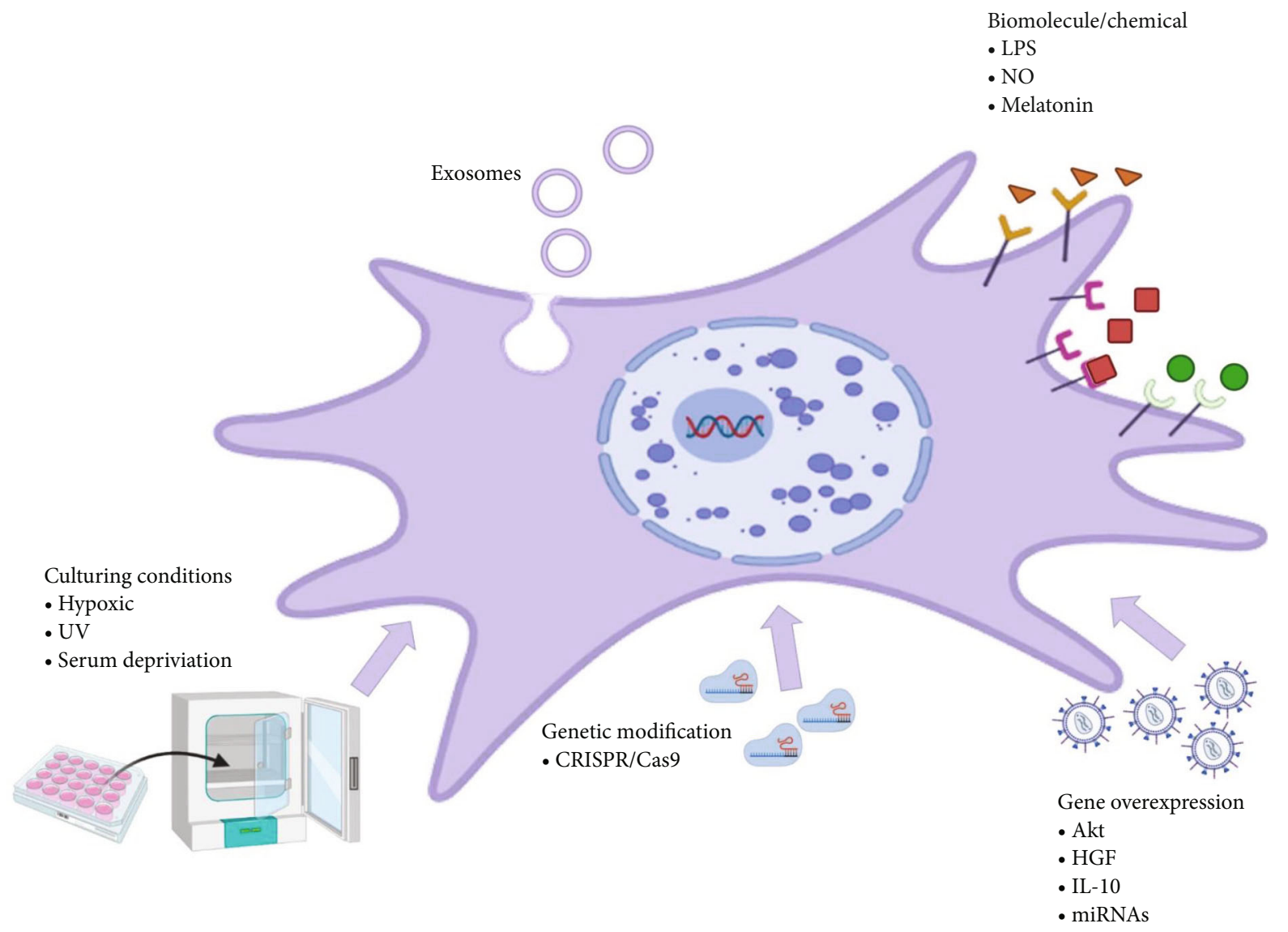

Figure 6: Preconditioning approaches to enhance the secretion and therapeutic efficacy of exosomes. The yield of secretome can be increased by preconditioning strategies such as introducing hypoxic and serum deprivation culture conditions and genetic modification using CRISPR technology as well as overexpression of certain genes. LPS: lipopolysaccharides; NO: nitric oxide; IL: interleukin; miRNAs: micro RNAs; UV: ultraviolet (created with BioRender.com).

HO1, IL-10, and VEGF expression, and suppress the expression of various apoptosis-related genes such as ICAM1, HIF1, NFkB, and IL-1 $\beta$ in a rat model [261]. Exosomes derived from deferoxamine-primed MSCs contained higher levels of miR-126a that support angiogenesis [262].

8.2.2. Genetic Modification. In 2010, a study reported that the paracrine factor secreted by MSC-overexpressed GATA-4 increased blood vessel formation and cell survival [263]. Next, in a mouse model of myocardial infarction, exosomes secreted by the genetically modified stem cells with GATA4 were more effective in increasing angiogenesis and reducing the number of apoptotic cardiac cells compared to the exosomes secreted by native stem cells [264]. MSC-derived exosomes that overexpress GATA-4 and CXCR4 have been shown to contain cardioprotective antiapoptotic miR-19a that activates Akt and ERK signaling pathways [265, 266]. Similarly, exosomes from MSCs that overexpress SDF-1 have been shown to prevent apoptosis of cardiomyocytes and exhibit improved cardiac regeneration properties [267]. Genetic modification methods have also been investigated to improve the therapeutic potential of exosomes for musculoskeletal disorders, liver and lung disorders, and inflammation-related disorders.
8.2.3. Combining Nanoparticles, Exosomes, and Stem Cells. Nanotechnology is the term used to cover the design, construction, and utilization of functional structures with at least one characteristic dimension measured in nanometers. In recent years, the application of nanotechnology in stem cells has made great advances. Currently, nanotechnology is utilized to control the proliferation and differentiation of the transplanted stem cells.

Carbon nanotubes (CNTs) are widely used in various fields, including medicinal chemistry, molecular electronics, and tissue engineering, due to their unique mechanical, physical, and chemical properties. CNTs can be designed and filled with DNA or peptide molecules to improve their properties and functions, such as biocompatibility and recognition capability in the molecular treatment of diseases [268270]. In a study that examined the effect of CNTs on the proliferation and differentiation of human stem cells, the result showed that CNTs inhibit the proliferation of cells of the embryonic kidney cell line HK293 and reduce the adhesion efficiency of cells in a dose- and time-dependent manner, but similar CNTs can stimulate the formation of bumps on the surface of human osteoblasts and fibroblasts, which are one of the active cells in the immune response [271]. Nanomaterials such as CNTs have enormous potential in the field 
of regenerative medicine in several areas, including (1) the development of nanovehicles to deliver biomolecule-based products to MSCs and (2) the creation of new biomedical applications for electroactive CNTs in combination with MSCs. However, despite the immense potential of nanoparticles, the method of delivering nanoparticles to the target cells was still a major problem. The maximum size of particles entering cells is $25 \mathrm{~nm}$ to $700 \mathrm{~nm}$; so, it is difficult for nanosized particles to penetrate cells due to the tension and adhesion strength of the cell surface. As an alternative, the nanoparticles can be bonded to the external cell membrane.

\section{Conclusion}

Regenerative medicine holds an immense potential for a variety of diseases in which there is a high unmet clinical need. Regenerative medicine covered a wide range of subbranches including cell and gene therapies and tissue engineering applications. Stem cells have been the focus for years because of their biological potential, and paracrine effect is the pivotal mechanism in stem cell-based tissue regeneration. Thus, cell secretome has attracted great attention as therapeutics in recent years and has been suggested as alternative to stem cell therapy as cell-free agents. The high degree of confidence in cell-based therapy is vividly indicated by the significant increase in the number of ongoing and planned clinical trials worldwide. Despite the relatively slow rate of translational success from laboratory to clinics, expectations, optimism, and excitement surrounding this field remain great.

\section{Data Availability}

No data were used to support this study.

\section{Conflicts of Interest}

The authors declare that there are no conflicts of interest.

\section{Acknowledgments}

This work was funded by the Fundamental Research Grant Scheme (FRGS/1/2020/SKK0/UKM/02/5) provided by the Ministry of Higher Education Malaysia.

\section{References}

[1] J. Yang, S. Li, X. B. He, C. Cheng, and W. Le, "Induced pluripotent stem cells in Alzheimer's disease: applications for disease modeling and cell-replacement therapy," Molecular Neurodegeneration, vol. 11, no. 1, p. 39, 2016.

[2] H. Wang, X. Yan, Y. Jiang, Z. Wang, Y. Li, and Q. Shao, “The human umbilical cord stem cells improve the viability of OA degenerated chondrocytes," Molecular Medicine Reports, vol. 17, no. 3, pp. 4474-4482, 2018.

[3] H. J. Jin, Y. K. Bae, M. Kim et al., "Comparative analysis of human mesenchymal stem cells from bone marrow, adipose tissue, and umbilical cord blood as sources of cell therapy," International Journal of Molecular Sciences, vol. 14, no. 9, pp. 17986-18001, 2013.
[4] L. Daneshmandi, S. Shah, T. Jafari et al., "Emergence of the stem cell secretome in regenerative engineering," Trends in Biotechnology, vol. 38, no. 12, pp. 1373-1384, 2020.

[5] K. Guthrie, A. Bruce, N. Sangha, E. Rivera, and J. Basu, "Potency evaluation of tissue engineered and regenerative medicine products," Trends in Biotechnology, vol. 31, no. 9, pp. 505-514, 2013.

[6] J. Basu and J. W. Ludlow, "Cell-based therapeutic products: potency assay development and application," Regenerative Medicine, vol. 9, no. 4, pp. 497-512, 2014.

[7] D. Drago, C. Cossetti, N. Iraci et al., "The stem cell secretome and its role in brain repair," Biochimie, vol. 95, no. 12, pp. 2271-2285, 2013.

[8] A. Geiger, A. Walker, and E. Nissen, "Human fibrocytederived exosomes accelerate wound healing in genetically diabetic mice," Biochemical and Biophysical Research Communications, vol. 467, no. 2, pp. 303-309, 2015.

[9] C. Tran and M. S. Damaser, "Stem cells as drug delivery methods: application of stem cell secretome for regeneration," Advanced Drug Delivery Reviews, vol. 82-83, pp. 1-11, 2015.

[10] G. D. Kusuma, J. Carthew, R. Lim, and J. E. Frith, "Effect of the microenvironment on mesenchymal stem cell paracrine signaling: opportunities to engineer the therapeutic effect," Stem Cells and Development, vol. 26, no. 9, pp. 617-631, 2017.

[11] K. Comella, M. Parlo, R. Daly et al., "Safety analysis of autologous stem cell therapy in a variety of degenerative diseases and injuries using the stromal vascular fraction," Journal of Clinical Medicine Research, vol. 9, no. 11, pp. 935-942, 2017.

[12] T. S. de Windt, L. A. Vonk, I. C. M. Slaper-Cortenbach et al., "Allogeneic mesenchymal stem cells stimulate cartilage regeneration and are safe for single-stage cartilage repair in humans upon mixture with recycled autologous chondrons," Stem Cells, vol. 35, no. 1, pp. 256-264, 2017.

[13] J. Liang, H. Zhang, C. Zhao et al., "Effects of allogeneic mesenchymal stem cell transplantation in the treatment of liver cirrhosis caused by autoimmune diseases," International Journal of Rheumatic Diseases, vol. 20, no. 9, pp. 12191226, 2017.

[14] P. Lohan, N. Murphy, O. Treacy et al., "Third-party allogeneic mesenchymal stromal cells prevent rejection in a pre-sensitized high-risk model of corneal transplantation," Frontiers in Immunology, vol. 9, article 2666, 2018.

[15] M. Nawaz, F. Fatima, K. C. Vallabhaneni et al., "Extracellular vesicles: evolving factors in stem cell biology," Stem Cells International, vol. 2016, Article ID 1073140, 17 pages, 2016.

[16] L. Bacakova, J. Zarubova, M. Travnickova et al., "Stem cells: their source, potency and use in regenerative therapies with focus on adipose-derived stem cells - a review," Biotechnology Advances, vol. 36, no. 4, pp. 1111-1126, 2018.

[17] A. Posabella, A. B. Alber, H. J. Undeutsch et al., "Derivation of thyroid follicular cells from pluripotent stem cells: insights from development and implications for regenerative medicine," Frontiers in Endocrinology, vol. 12, pp. 1-16, 2021.

[18] A. Arauchi, K. Matsuura, T. Shimizu, and T. Okano, "Functional thyroid follicular cells differentiation from humaninduced pluripotent stem cells in suspension culture," Frontiers in Endocrinology, vol. 8, p. 103, 2017.

[19] A. A. Kurmann, M. Serra, F. Hawkins et al., "Regeneration of thyroid function by transplantation of differentiated 
pluripotent stem cells," Cell Stem Cell, vol. 17, no. 5, pp. 527542, 2015.

[20] E. Ito, S. Miyagawa, M. Takeda et al., "Tumorigenicity assay essential for facilitating safety studies of hi PSC-derived cardiomyocytes for clinical application," Scientific Reports, vol. 9, no. 1, pp. 1-10, 2019.

[21] M. Mandai, A. Watanabe, Y. Kurimoto et al., “Autologous induced stem-cell-derived retinal cells for macular degeneration," New England Journal of Medicine, vol. 376, no. 11, pp. 1038-1046, 2017.

[22] H. Kanemura, M. J. Go, M. Shikamura et al., “Tumorigenicity studies of induced pluripotent stem cell (iPSC)-derived retinal pigment epithelium (RPE) for the treatment of agerelated macular degeneration," PLoS One, vol. 9, no. 1, pp. 1-11, 2014.

[23] A. A. Dayem, S. B. Lee, K. Kim et al., "Production of mesenchymal stem cells through stem cell reprogramming," International Journal of Molecular Sciences, vol. 20, no. 8, pp. 142, 2019.

[24] A. R. Quinlan, M. J. Boland, M. L. Leibowitz et al., "Genome sequencing of mouse induced pluripotent stem cells reveals retroelement stability and infrequent DNA rearrangementduring reprogramming," Cell Stem Cell, vol. 9, no. 4, pp. 366-373, 2011.

[25] L. C. Laurent, I. Ulitsky, I. Slavin et al., "Dynamic changes in the copy number of pluripotency and cell proliferation genes in human ES and iPS cells during reprogramming and time in culture," Cell, vol. 8, no. 1, pp. 106-118, 2012.

[26] B. Johannesson, I. Sagi, A. Gore et al., "Comparable frequencies of coding mutations and loss of imprinting in human pluripotent cells derived by nuclear transfer and defined factors," Cell Stem Cell, vol. 15, no. 5, pp. 634-642, 2014.

[27] G. Itakura, S. Kawabata, M. Ando et al., "Fail-safe system against potential tumorigenicity after transplantation of iPSC derivatives," Stem Cell Reports, vol. 8, no. 3, pp. 673-684, 2017.

[28] A. Lipus, E. Janosz, M. Ackermann et al., "Targeted integration of inducible caspase-9 in human iPSCs allows efficient in vitro clearance of iPSCs and iPSC-macrophages," International Journal of Molecular Sciences, vol. 21, no. 7, article 2481, 2020.

[29] D. Mushahary, A. Spittler, C. Kasper, V. Weber, and V. Charwat, "Isolation, cultivation, and characterization of human mesenchymal stem cells," Cytometry A, vol. 93, no. 1, pp. 19-31, 2018.

[30] M. N. F. B. Hassan, M. D. Yazid, M. H. M. Yunus et al., "Large-scale expansion of human mesenchymal stem cells," Stem Cells International, vol. 2020, Article ID 9529465, 17 pages, 2020.

[31] L. L. Liau, M. E. Al-Masawa, B. Koh et al., "The potential of mesenchymal stromal cell as therapy in neonatal diseases," Frontiers in Pediatrics, vol. 8, article 591693, 2020.

[32] Q. H. Looi, S. P. Eng, L. L. Liau et al., "Mesenchymal stem cell therapy for sports Injuries - From research to clinical practice," Sains Malaysiana, vol. 49, no. 4, pp. 825-838, 2020.

[33] L. L. Liau, B. H. I. Ruszymah, M. H. Ng, and J. X. Law, "Characteristics and clinical applications of Wharton's jelly-derived mesenchymal stromal cells," Current Research in Translational Medicine, vol. 68, no. 1, pp. 5-16, 2020.

[34] S. Shin, J. Lee, Y. Kwon et al., "Comparative proteomic analysis of the mesenchymal stem cells secretome from adipose, bone marrow, placenta and wharton's jelly," International Journal of Molecular Sciences, vol. 22, no. 2, pp. 1-17, 2021.

[35] J. L. Spees, R. H. Lee, and C. A. Gregory, "Mechanisms of mesenchymal stem/stromal cell function," Stem Cell Research \& Therapy, vol. 7, no. 1, pp. 125-125, 2016.

[36] M. Gnecchi, P. Danieli, G. Malpasso, and M. C. Ciuffreda, Paracrine mechanisms of mesenchymal stem cells in tissue repair, Springer, 2016.

[37] L. da Silva Meirelles, A. M. Fontes, D. T. Covas, and A. I. Caplan, "Mechanisms involved in the therapeutic properties of mesenchymal stem cells," Cytokine \& Growth Factor Reviews, vol. 20, no. 5-6, pp. 419-427, 2009.

[38] F. Fatima, K. Ekstrom, I. Nazarenko et al., "Non-coding RNAs in mesenchymal stem cell-derived extracellular vesicles: deciphering regulatory roles in stem cell potency, inflammatory resolve, and tissue regeneration," Frontiers in Genetics, vol. 8, p. 161, 2017.

[39] Q. Zhao, H. Ren, and Z. Han, "Mesenchymal stem cells: Immunomodulatory capability and clinical potential in immune diseases," Journal of Cellular Immunotherapy, vol. 2, no. 1, pp. 3-20, 2016.

[40] K. English, J. M. Ryan, L. Tobin, M. J. Murphy, F. P. Barry, and B. P. Mahon, "Cell contact, prostaglandin E2and transforming growth factor beta 1 play non-redundant roles in human mesenchymal stem cell induction of CD4 +CD25Highforkhead box P3+regulatory T cells," Clinical and Experimental Immunology, vol. 156, no. 1, pp. 149-160, 2009.

[41] A. Pourgholaminejad, N. Aghdami, H. Baharvand, and S. M. Moazzeni, "The effect of pro-inflammatory cytokines on immunophenotype, differentiation capacity and immunomodulatory functions of human mesenchymal stem cells," Cytokine, vol. 85, pp. 51-60, 2016.

[42] A. Augello, R. Tasso, S. M. Negrini et al., "Bone marrow mesenchymal progenitor cells inhibit lymphocyte proliferation by activation of the programmed death 1 pathway," European Journal of Immunology, vol. 35, no. 5, pp. 1482-1490, 2005.

[43] A. Nasef, A. Chapel, C. Mazurier et al., "Identification of IL10 and TGF-beta transcripts involved in the inhibition of Tlymphocyte proliferation during cell contact with human mesenchymal stem cells," Gene Expression, vol. 13, no. 4-5, pp. 217-226, 2007.

[44] M. Loibl, A. Binder, M. Herrmann et al., "Direct Cell-Cell Contact between Mesenchymal Stem Cells and Endothelial Progenitor Cells Induces a Pericyte-Like Phenotype In Vitro," BioMed Research International, vol. 2014, Article ID 395781, 10 pages, 2014.

[45] H. K. Lee, E. Y. Kim, H. S. Kim et al., "Effect of Human Mesenchymal Stem Cells on Xenogeneic T and B Cells Isolated from Lupus-Prone MRL.Faslpr Mice," Stem Cells International, vol. 2020, Article ID 5617192, 10 pages, 2020.

[46] S. P. Chin, M. Y. Mohd-Shahrizal, M. Z. Liyana, K. Y. Then, and S. K. Cheong, "High dose of intravenous allogeneic umbilical cord-derived mesenchymal stem cells (CLV-100) infusion displays better immunomodulatory effect among healthy volunteers: a phase 1 clinical study," Stem Cells International, vol. 2020, Article ID 8877003, 13 pages, 2020.

[47] J. Wang, W. Zhang, G. H. He, B. Wu, and S. Chen, "Transfection with CXCR4 potentiates homing of mesenchymal stem cells in vitro and therapy of diabetic retinopathy in vivo," International Journal of Ophthalmology, vol. 11, no. 5, pp. 766-772, 2018. 
[48] J. Fan, X. Tang, Q. Wang et al., "Mesenchymal stem cells alleviate experimental autoimmune cholangitis through immunosuppression and cytoprotective function mediated by galectin-9," Stem Cell Research and Therapy, vol. 9, no. 1, pp. 1-12, 2018.

[49] F. Liu, H. Qiu, M. Xue et al., "MSC-secreted TGF- $\beta$ regulates lipopolysaccharide-stimulated macrophage M2-like polarization via the Akt/Fox O1 pathway," Stem Cell Research and Therapy, vol. 87, pp. 1-14, 2019.

[50] A. Haghighitalab, M. M. Matin, A. Amin et al., "Investigating the effects of IDO1, PTGS2, and TGF- $\beta 1$ overexpression on immunomodulatory properties of hTERT-MSCs and their extracellular vesicles," Scientific Reports, vol. 11, no. 1, pp. 1-19, 2021.

[51] L. Maertens, C. Erpicum, B. Detry et al., "Bone marrowderived mesenchymal stem cells drive lymphangiogenesis," PLoS One, vol. 9, no. 9, article e106976, 2014.

[52] H. El-Gendy, S. E. D. Hawass, M. Awad et al., "Comparative study between human mesenchymal stem cells and etanercept as immunomodulatory agents in rat model of rheumatoid arthritis," Immunologic Research, vol. 68, no. 5, pp. 255-268, 2020.

[53] S. Shin, Y. Kim, S. Jeong et al., "The therapeutic effect of human adult stem cells derived from adipose tissue in endotoxemic rat model," International Journal of Medical Sciences, vol. 10, no. 1, pp. 8-18, 2013.

[54] R. Tinoco, V. Alcalde, Y. Yang, K. Sauer, and E. I. Zuniga, "Cell-intrinsic transforming growth factor- $\beta$ signaling mediates virus-specific CD8+ T cell deletion and viral persistence in vivo," Immunity, vol. 31, no. 1, pp. 145-157, 2009.

[55] M. M. Rosado, M. E. Bernardo, M. Scarsella et al., "Inhibition of B-cell proliferation and antibody production by mesenchymal stromal cells is mediated by T cells," Stem Cells and Development, vol. 24, no. 1, pp. 93-103, 2015.

[56] D. J. Weiss, K. English, A. Krasnodembskaya, J. M. Isaza-Correa, I. J. Hawthorne, and B. P. Mahon, "The necrobiology of mesenchymal stromal cells affects therapeutic efficacy," Frontiers in Immunology, vol. 10, pp. 1-12, 2019.

[57] R. R. Goodman and J. E. Davies, "Mesenchymal Stromal Cells and Their derivatives - putative Therapeutics in the Management of Autoimmune Pancreatitis," FEBS Open Bio, vol. 10, no. 6, pp. 969-978, 2020.

[58] J. Galipeau, M. Krampera, K. Leblanc et al., "Mesenchymal stromal cell variables influencing clinical potency: the impact of viability, fitness, route of Administration and Host Predisposition," Cytotherapy, vol. 23, no. 5, pp. 368-372, 2021.

[59] N. Bazhanov, J. H. Ylostalo, T. J. Bartosh et al., "Intraperitoneally infused human mesenchymal stem cells form aggregates with mouse immune cells and attach to peritoneal organs," Stem Cell Research and Therapy, vol. 7, no. 1, pp. 1-14, 2016.

[60] E. Eggenhofer, V. Benseler, A. Kroemer et al., "Mesenchymal stem cells are short-lived and do not migrate beyond the lungs after intravenous infusion," Frontiers in Immunology, vol. 3, p. 297, 2012.

[61] X. Li, B. Shang, Y.-n. Li, Y. Shi, and C. Shao, "IFN $\gamma$ and TNF $\alpha$ synergistically induce apoptosis of mesenchymal stem/stromal cells via the induction of nitric oxide," Stem Cell Research \& Therapy, vol. 10, no. 18, pp. 1-11, 2019.

[62] Y. Liu, L. Wang, T. Kikuiri et al., "Mesenchymal stem cellbased tissue regeneration is gverned by recipient $\mathrm{T}$ lympho- cyte via IFN- $\gamma$ and TNF- $\alpha$," Nature Medicine, vol. 17, no. 12, pp. 1594-1601, 2012.

[63] P. Mancuso, A. J. Burke, S. Raman et al., "Mesenchymal stem cell therapy for osteoarthritis: how apoptotic cells modulate inflammation," Osteoarthritis and Cartilage, vol. 26, pp. S297-S297, 2018.

[64] C. L. Chang, S. Leu, H. C. Sung et al., "Impact of apoptotic adipose-derived mesenchymal stem cells on attenuating organ damage and reducing mortality in rat sepsis syndrome induced by cecal puncture and ligation," Journal of Translational Medicine, vol. 10, no. 1, p. 1, 2012.

[65] T. S. Cheung, A. Galleu, M. von Bonin, M. Bornhäuser, and F. Dazzi, "Apoptotic mesenchymal stromal cells induce prostaglandin E2 in monocytes: implications for the monitoring of mesenchymal stromal cell activity," Haematologica, vol. 104, pp. 438-441, 2019.

[66] N. Amin, X. Tan, Q. Ren et al., "Recent advances of induced pluripotent stem cells application in neurodegenerative diseases," Progress in Neuro-Psychopharmacology and Biological Psychiatry, vol. 95, article 109674, 2019.

[67] L. Gao, S. Cen, P. Wang et al., "Autophagy improves the immunosuppression of CD4+T cells by mesenchymal stem cells through transforming growth Factor- $\beta 1$," Stem Cells Translational Medicine, vol. 5, no. 11, pp. 1496-1505, 2016.

[68] B. Lv, T. Hua, F. Li et al., "Hypoxia-inducible factor $1 \alpha$ protects mesenchymal stem cells against oxygen-glucose deprivation-induced injury via autophagy induction and PI3K/AKT/mTOR signaling pathway," American Journal of Translational Research, vol. 9, no. 5, pp. 2492-2499, 2017.

[69] Z. Zhang, C. Yang, M. Shen et al., "Autophagy mediates the beneficial effect of hypoxic preconditioning on bone marrow mesenchymal stem cells for the therapy of myocardial infarction," Stem Cell Research and Therapy, vol. 8, no. 1, pp. 1-17, 2017.

[70] B. Wang, H. Jia, B. Zhang et al., "Pre-incubation with huc MSC-exosomes prevents cisplatin-induced nephrotoxicity by activating autophagy," Stem Cell Research and Therapy, vol. 8, no. 1, pp. 1-14, 2017.

[71] J. Hou, Z. P. Han, Y. Y. Jing et al., “Autophagy prevents irradiation injury and maintains stemness through decreasing ROS generation in mesenchymal stem cells," Cell Death and Disease, vol. 4, no. 10, pp. 1-10, 2013.

[72] H. J. Park, J. Y. Shin, H. N. Kim, S. H. Oh, and P. H. Lee, "Neuroprotective effects of mesenchymal stem cells through autophagy modulation in a Parkinsonian model," Neurobiology of Aging, vol. 35, no. 8, pp. 1920-1928, 2014.

[73] N. Tseng, S. C. Lambie, C. Q. Huynh et al., "Mitochondrial transfer from mesenchymal stem cells improves neuronal metabolism after oxidant injury in vitro: the role of miro 1," Journal of Cerebral Blood Flow and Metabolism, vol. 41, no. 4, pp. 761-770, 2021.

[74] C. Li, M. K. H. Cheung, S. Han et al., "Mesenchymal stem cells and their mitochondrial transfer: a double-edged sword," Bioscience Reports, vol. 39, no. 5, article BSR20182417, 2019.

[75] D. Liu, Y. Gao, J. Liu et al., "Intercellular mitochondrial transfer as a means of tissue revitalization," Signal Transduction and Targeted Therapy, vol. 6, no. 1, p. 65, 2021.

[76] T. Ahmad, S. Mukherjee, B. Pattnaik et al., "Miro1 regulates intercellular mitochondrial transport \&amp; enhances mesenchymal stem cell rescue efficacy," The EMBO Journal, vol. 33, no. 9, pp. 994-1010, 2014. 
[77] C. Théry, K. W. Witwer, E. Aikawa et al., "Minimal information for studies of extracellular vesicles 2018 (MISEV 2018): a position statement of the International Society for Extracellular Vesicles and update of the MISEV2014 guidelines," Journal of Extracellular Vesicles, vol. 7, no. 1, article 1535750, 2018.

[78] W. Lin, L. Huang, Y. Li et al., "Mesenchymal stem cells and cancer: clinical challenges and opportunities," BioMed Research International, vol. 2019, Article ID 2820853, 12 pages, 2019.

[79] H. Ni, S. Yang, F. Siaw-Debrah et al., "Exosomes derived from bone mesenchymal stem cells ameliorate early inflammatory responses following traumatic brain injury," Frontiers in Neuroscience, vol. 13, p. 14, 2019.

[80] Z. Li, F. Liu, X. He, X. Yang, F. Shan, and J. Feng, "Exosomes derived from mesenchymal stem cells attenuate inflammation and demyelination of the central nervous system in EAE rats by regulating the polarization of microglia," International Immunopharmacology, vol. 67, pp. 268-280, 2019.

[81] F. Mao, Y. Wu, X. Tang et al., "Exosomes derived from human umbilical cord mesenchymal stem cells relieve inflammatory bowel disease in mice," BioMed Research International, vol. 2017, Article ID 5356760, 12 pages, 2017.

[82] M. S. Pavlyukov, H. Yu, S. Bastola et al., "Apoptotic cellderived extracellular vesicles promote malignancy of glioblastoma via intercellular transfer of splicing factors," Cancer Cell, vol. 34, no. 1, pp. 119-135.e10, 2018.

[83] S. Caruso and I. K. H. Poon, "Apoptotic cell-derived extracellular vesicles: More than just debris," Frontiers in Immunology, vol. 9, pp. 1486-1486, 2018.

[84] R. Kakarla, J. Hur, Y. J. Kim, J. Kim, and Y.-J. Chwae, "Apoptotic cell-derived exosomes: messages from dying cells," Experimental \& Molecular Medicine, vol. 52, no. 1, pp. 1-6, 2020.

[85] A. Meiliana, N. M. Dewi, and A. Wijaya, "Mesenchymal stem cell secretome: Cell-free therapeutic strategy in regenerative medicine," The Indonesian Biomedical Journal, vol. 11, no. 2, pp. 113-124, 2019.

[86] L. A. Pokrovskaya, E. V. Zubareva, S. V. Nadezhdin, A. S. Lysenko, and T. L. Litovkina, "Biological activity of mesenchymal stem cells secretome as a basis for cell-free therapeutic approach," Research Results in Pharmacology, vol. 6, no. 1, pp. 57-68, 2020.

[87] C. J. Cunningham, E. Redondo-Castro, and S. M. Allan, “The therapeutic potential of the mesenchymal stem cell secretome in ischaemic stroke," Journal of Cerebral Blood Flow \& Metabolism, vol. 38, no. 8, pp. 1276-1292, 2018.

[88] D.-C. Ding, W.-C. Shyu, M.-F. Chiang et al., "Enhancement of neuroplasticity through upregulation of $\beta 1$-integrin in human umbilical cord-derived stromal cell implanted stroke model," Neurobiology of Disease, vol. 27, no. 3, pp. 339-353, 2007.

[89] Y.-T. Lin, Y. Chern, C.-K. J. Shen et al., "Human mesenchymal stem cells prolong survival and ameliorate motor deficit through trophic support in Huntington's disease mouse models," PloS One, vol. 6, no. 8, article e22924, 2011.

[90] F. Wang, T. Yasuhara, T. Shingo et al., "Intravenous administration of mesenchymal stem cells exerts therapeutic effects on parkinsonian model of rats: focusing on neuroprotective effects of stromal cell-derived factor- $1 \alpha$," BMC Neuroscience, vol. 11, no. 1, pp. 1-9, 2010.
[91] S. S. Collawn and S. Patel, "Adipose-derived stem cells, their secretome, and wound healing," Journal of Cell Science \& Therapy, vol. 5, no. 3, p. 1, 2014.

[92] T. G. Ebrahimian, F. Pouzoulet, C. Squiban et al., "Cell therapy based on adipose tissue-derived stromal cells promotes physiological and pathological wound healing," Arteriosclerosis, Thrombosis and Vascular Biology, vol. 29, no. 4, pp. 503510, 2009.

[93] S.-P. Huang, C.-H. Huang, J.-F. Shyu et al., "Promotion of wound healing using adipose-derived stem cells in radiation ulcer of a rat model," Journal of Biomedical Science, vol. 20, no. 1, pp. 1-10, 2013.

[94] A. Zografou, O. Papadopoulos, C. Tsigris et al., "Autologous transplantation of adipose-derived stem cells enhances skin graft survival and wound healing in diabetic rats," Annals of Plastic Surgery, vol. 71, no. 2, pp. 225-232, 2013.

[95] P. Ahangar, S. J. Mills, and A. J. Cowin, "Mesenchymal stem cell secretome as an emerging cell-free alternative for improving wound repair," International Journal of Molecular Sciences, vol. 21, no. 19, article 7038, 2020.

[96] D. Kehl, M. Generali, A. Mallone et al., "Proteomic analysis of human mesenchymal stromal cell secretomes: a systematic comparison of the angiogenic potential," NPJ Regenerative Medicine, vol. 4, no. 1, pp. 1-13, 2019.

[97] R. Mitchell, B. Mellows, J. Sheard et al., "Secretome of adipose-derived mesenchymal stem cells promotes skeletal muscle regeneration through synergistic action of extracellular vesicle cargo and soluble proteins," Stem Cell Research \& Therapy, vol. 10, no. 1, p. 116, 2019.

[98] Y. Wang, W. Long, Y. Cao, J. Li, L. You, and Y. Fan, "Mesenchymal stem cell-derived secretomes for therapeutic potential of premature infant diseases," Bioscience Reports, vol. 40, no. 5, article BSR20200241, 2020.

[99] B. Al-Azzawi, D. H. McGuigan, F. N. M. Koivula et al., "The secretome of mesenchymal stem cells prevents islet beta cell apoptosis via an IL-10-dependent mechanism," The Open Stem Cell Journal, vol. 6, no. 1, pp. 1-12, 2020.

[100] W.-T. Hsu, C.-H. Lin, B.-L. Chiang, H.-Y. Jui, K. K.-Y. Wu, and C.-M. Lee, "Prostaglandin E2Potentiates Mesenchymal Stem Cell-Induced IL-10+IFN- $\gamma+$ CD4+Regulatory T Cells To Control Transplant Arteriosclerosis," The Journal of Immunology, vol. 190, no. 5, pp. 2372-2380, 2013.

[101] K. Ogata, M. Osugi, T. Kawai et al., "Secretomes of mesenchymal stem cells induce early bone regeneration by accelerating migration of stem cells," Journal of Oral and Maxillofacial Surgery, Medicine, and Pathology, vol. 30, no. 5, pp. 445-451, 2018.

[102] Y. Qin, L. Wang, Z. Gao, G. Chen, and C. Zhang, "Bone marrow stromal/stem cell-derived extracellular vesicles regulate osteoblast activity and differentiation in vitro and promote bone regeneration in vivo," Scientific Reports, vol. 6, no. 1, pp. 1-11, 2016.

[103] S. Eleuteri and A. Fierabracci, "Insights into the secretome of mesenchymal stem cells and its potential applications," International Journal of Molecular Sciences, vol. 20, no. 18, article 4597, 2019.

[104] H. Xin, Y. Li, Y. Cui, J. J. Yang, Z. G. Zhang, and M. Chopp, "Systemic administration of exosomes released from mesenchymal stromal cells promote functional recovery and neurovascular plasticity after stroke in rats," Journal of Cerebral Blood Flow \& Metabolism, vol. 33, no. 11, pp. 1711-1715, 2013. 
[105] L.-P. Zhu, T. Tian, J.-Y. Wang et al., "Hypoxia-elicited mesenchymal stem cell-derived exosomes facilitates cardiac repair through miR-125b-mediated prevention of cell death in myocardial infarction," Theranostics, vol. 8, no. 22, pp. 6163-6177, 2018.

[106] X. Zou, G. Zhang, Z. Cheng et al., "Microvesicles derived from human Wharton's Jelly mesenchymal stromal cells ameliorate renal ischemia-reperfusion injury in rats by suppressing CX3CL1," Stem Cell Research \& Therapy, vol. 5, no. 2, pp. 1-13, 2014.

[107] L. Mazini, L. Rochette, B. Admou, S. Amal, and G. Malka, "Hopes and limits of adipose-derived stem cells (ADSCs) and mesenchymal stem cells (MSCs) in wound healing," International Journal of Molecular Sciences, vol. 21, no. 4, article 1306, 2020.

[108] Q. Wu, F. K. Ji, J. H. Wang, H. Nan, and D. L. Liu, “Stromal cell-derived factor 1 promoted migration of adipose-derived stem cells to the wounded area in traumatic rats," Biochemical and Biophysical Research Communications, vol. 467, no. 1, pp. 140-145, 2015.

[109] X. Yu, D. Chen, Y. Zhang et al., "Overexpression of CXCR4 in mesenchymal stem cells promotes migration, neuroprotection and angiogenesis in a rat model of stroke," Journal of the Neurological Sciences, vol. 316, no. 1-2, pp. 141-149, 2012.

[110] D. Zhang, G. C. Fan, X. Zhou et al., "Over-expression of CXCR4 on mesenchymal stem cells augments myoangiogenesis in the infarcted myocardium," Journal of Molecular and Cellular Cardiology, vol. 44, no. 2, pp. 281-292, 2008.

[111] L. Fu, G. Liu, A. Halim, Y. Ju, Q. Luo, and A. G. Song, "Mesenchymal Stem Cell Migration and Tissue Repair," Cells, vol. 8, no. 8, p. 784, 2019.

[112] Y. Qin, Z. Zhou, F. Zhang et al., "Induction of regulatory Bcells by mesenchymal stem cells is affected by SDF- $1 \alpha$ CXCR7," Cellular Physiology and Biochemistry, vol. 37, no. 1, pp. 117-130, 2015.

[113] X. B. Zheng, X. W. He, L. J. Zhang et al., "Bone marrowderived CXCR4-overexpressing MSCs display increased homing to intestine and ameliorate colitis-associated tumorigenesis in mice," Gastroenterology Report, vol. 7, no. 2, pp. 127-138, 2019.

[114] M. Lim, W. Wang, L. Liang et al., "Intravenous injection of allogeneic umbilical cord-derived multipotent mesenchymal stromal cells reduces the infarct area and ameliorates cardiac function in a porcine model of acute myocardial infarction," Stem Cell Research and Therapy, vol. 9, no. 1, pp. 1-17, 2018.

[115] L. L. Liau, Q. H. Looi, W. C. Chia, T. Subramaniam, M. H. $\mathrm{Ng}$, and J. X. Law, "Treatment of spinal cord injury with mesenchymal stem cells," Cell \& Bioscience, vol. 10, no. 1, p. ???, 2020.

[116] H. Al Faqeh, B. M. Y. Nor Hamdan, H. C. Chen, B. S. Aminuddin, and B. H. I. Ruszymah, "The potential of intraarticular injection of chondrogenic-induced bone marrow stem cells to retard the progression of osteoarthritis in a sheep model," Experimental Gerontology, vol. 47, no. 6, pp. 458464, 2012.

[117] S. Zhang, S. J. Chuah, R. C. Lai, J. H. P. Hui, S. K. Lim, and W. S. Toh, "MSC exosomes mediate cartilage repair by enhancing proliferation, attenuating apoptosis and modulating immune reactivity," Biomaterials, vol. 156, pp. 16-27, 2018.

[118] A. Kurtz, "Mesenchymal stem cell delivery routes and fate," International Journal of Stem Cells, vol. 1, no. 1, pp. 1-7, 2008.
[119] A. J. Kanelidis, C. Premer, J. Lopez, W. Balkan, and J. M. Hare, "Route of delivery modulates the efficacy of mesenchymal stem cell therapy for myocardial infarction: a metaanalysis of preclinical studies and clinical trials," Circulation Research, vol. 120, no. 7, pp. 1139-1150, 2017.

[120] M. Klass, V. Gavrikov, D. Drury et al., "Intravenous mononuclear marrow cells reverse neuropathic pain from experimental mononeuropathy," Anesthesia \& Analgesia, vol. 104, no. 4, pp. 944-948, 2007.

[121] M. T. Harting, F. Jimenez, H. Xue et al., "Intravenous mesenchymal stem cell therapy for traumatic brain injury," Journal of Neurosurgery, vol. 110, no. 6, pp. 1189-1197, 2009.

[122] A. C. Vandergriff, J. B. M. de Andrade, J. Tang et al., "Intravenous cardiac stem cell-derived exosomes ameliorate cardiac dysfunction in doxorubicin induced dilated cardiomyopathy," Stem Cells International, vol. 2015, Article ID 960926, 8 pages, 2015.

[123] J.-y. Chen, R. An, Z.-j. Liu et al., “Therapeutic effects of mesenchymal stem cell-derived microvesicles on pulmonary arterial hypertension in rats," Acta Pharmacologica Sinica, vol. 35, no. 9, pp. 1121-1128, 2014.

[124] R. Keyhanmanesh, R. Rahbarghazi, M. R. Aslani, M. Hassanpour, and M. Ahmadi, "Systemic delivery of mesenchymal stem cells condition media in repeated doses acts as magic bullets in restoring IFN- $\gamma / \mathrm{IL}-4$ balance in asthmatic rats," Life Sciences, vol. 212, pp. 30-36, 2018.

[125] J. L. Tan, S. N. Lau, B. Leaw et al., "Amnion epithelial cellderived exosomes restrict lung injury and enhance endogenous lung repair," Stem Cells Translational Medicine, vol. 7, no. 2, pp. 180-196, 2018.

[126] X. Sun, A. Shan, Z. Wei, and B. Xu, "Intravenous mesenchymal stem cell-derived exosomes ameliorate myocardial inflammation in the dilated cardiomyopathy," Biochemical and Biophysical Research Communications, vol. 503, no. 4, pp. 2611-2618, 2018.

[127] G.-w. Hu, Q. Li, X. Niu et al., "Exosomes secreted by humaninduced pluripotent stem cell-derived mesenchymal stem cells attenuate limb ischemia by promoting angiogenesis in mice," Stem Cell Research \& Therapy, vol. 6, no. 1, pp. 1-15, 2015.

[128] C. Melzer, J. V. D. Ohe, and R. Hass, “Anti-tumor effects of exosomes derived from drug-incubated permanently growing human MSC," International Journal of Molecular Sciences, vol. 21, no. 19, article 7311, 2020.

[129] L. Wang, M. Chopp, A. Szalad et al., "Exosomes derived from schwann cells ameliorate peripheral neuropathy in type 2 diabetic mice," Diabetes, vol. 69, no. 4, pp. 749-759, 2020.

[130] V. Sengupta, S. Sengupta, A. Lazo, P. Woods, A. Nolan, and N. Bremer, "Exosomes derived from bone marrow mesenchymal stem cells as treatment for severe COVID-19," Stem Cells and Development, vol. 29, no. 12, pp. 747-754, 2020.

[131] Z. Rashidbenam, M. H. Jasman, P. Hafez et al., "Overview of urethral reconstruction by tissue engineering: current strategies, clinical status and future direction," Tissue Engineering and Regenerative Medicine, vol. 16, no. 4, pp. 365-384, 2019.

[132] A. Phadke, Y. S. Hwang, S. Hee Kim et al., "Effect of scaffold microarchitecture on osteogenic differentiation of human mesenchymal stem cells," European Cells and Materials, vol. 25, pp. 114-129, 2012.

[133] S. E. Enderami, M. Kehtari, M. F. Abazari et al., "Generation of insulin-producing cells from human induced pluripotent 
stem cells on PLLA/PVA nanofiber scaffold," Artificial Cells, Nanomedicine and Biotechnology, vol. 46, Supplement 1, pp. 1062-1069, 2018.

[134] M. F. Abazari, F. Soleimanifar, M. Nouri Aleagha et al., "PCL/PVA nanofibrous scaffold improve insulin-producing cells generation from human induced pluripotent stem cells," Gene, vol. 671, pp. 50-57, 2018.

[135] R. N. Mansour, G. Barati, M. Soleimani et al., "Generation of high-yield insulin producing cells from human-induced pluripotent stem cells on polyethersulfone nanofibrous scaffold," Artificial Cells, Nanomedicine and Biotechnology, vol. 46, Supplement 1, pp. 733-739, 2018.

[136] S. Nadri, G. Barati, H. Mostafavi, A. Esmaeilzadeh, and S. E. Enderami, "Differentiation of conjunctiva mesenchymal stem cells into secreting islet beta cells on plasma treated electrospun nanofibrous scaffold," Artificial Cells, Nanomedicine and Biotechnology, vol. 46, Supplement 1, pp. 178-187, 2018.

[137] R. Guo, M. Morimatsu, T. Feng et al., "Stem cell-derived cell sheet transplantation for heart tissue repair in myocardial infarction," Stem Cell Research \& Therapy, vol. 11, no. 1, p. 19, 2020.

[138] C. Imashiro and T. Shimizu, "Fundamental technologies and recent advances of cell-sheet-based tissue engineering," International Journal of Molecular Sciences, vol. 22, no. 1, p. 425, 2021.

[139] R. Ramezankhani, S. Torabi, N. Minaei et al., "Two decades of global progress in authorized advanced therapy medicinal products: an emerging revolution in therapeutic strategies," Frontiers in Cell and Developmental Biology, vol. 8, pp. 547653-547653, 2020.

[140] F. Meng, R. Xu, S. Wang et al., "Human umbilical cordderived mesenchymal stem cell therapy in patients with COVID-19: a phase 1 clinical trial," Signal Transduction and Targeted Therapy, vol. 5, no. 1, p. 172, 2020.

[141] D. C. Chambers, D. Enever, N. Ilic et al., "A phase 1b study of mesenchymal stromal cell therapy for idiopathic pulmonary fibrosis," Cytotherapy, vol. 16, no. 4, p. S12, 2014.

[142] J. G. Wilson, K. D. Liu, H. Zhuo et al., "Mesenchymal stem (stromal) cells for treatment of ARDS: a phase 1 clinical trial," The Lancet Respiratory Medicine, vol. 3, no. 1, pp. 24-32, 2015.

[143] C. Brizuela, G. Meza, D. Urrejola et al., “Cell-based regenerative endodontics for treatment of periapical lesions: a randomized, controlled phase I/II clinical trial," Journal of Dental Research, vol. 99, no. 5, pp. 523-529, 2020.

[144] D. Y. S. Tanikawa, C. C. G. Pinheiro, M. C. A. Almeida et al., "Deciduous dental pulp stem cells for maxillary alveolar reconstruction in cleft lip and palate patients," Stem Cells International, vol. 2020, Article ID 6234167, 9 pages, 2020.

[145] A. Vega, M. A. Martín-Ferrero, F. D. Canto et al., "Treatment of knee osteoarthritis with allogeneic bone marrow mesenchymal stem cells: a randomized controlled trial," Transplantation, vol. 99, no. 8, pp. 1681-1690, 2015.

[146] B. A. Tompkins, D. L. Difede, A. Khan et al., "Allogeneic mesenchymal stem cells ameliorate aging Frailty: a phase II randomized, double-blind, placebo-controlled clinical trial," Journal of gerontology, vol. 72, no. 11, pp. 15131522, 2017.

[147] R. Bolli, J. M. Hare, K. L. March et al., "Rationale and design of the CONCERT-HF trial (combination of mesenchymal and c-kit+Cardiac stem cells as regenerative therapy for heart failure)," Circulation Research, vol. 122, no. 12, pp. 17031715, 2018.

[148] R. Bolli, J. M. Hare, T. D. Henry et al., "Rationale and design of the SENECA (StEm cell iNjECtion in cAncer survivors) trial," American Heart Journal, vol. 201, pp. 54-62, 2018.

[149] J. M. Hare, J. E. Fishman, G. Gerstenblith et al., "Comparison of allogeneic vs autologous bone marrow-derived mesenchymal stem cells delivered by transendocardial injection in patients with ischemic cardiomyopathy," Journal of Autism and Developmental Disorders, vol. 47, no. 3, pp. 549-562, 2012.

[150] J. M. Hare, D. F. DL, A. C. Rieger et al., "Randomized Comparison of Allogeneic Versus Autologous Mesenchymal Stem Cells for Nonischemic Dilated Cardiomyopathy: POSEIDON-DCM Trial," Journal of the American College of Cardiology, vol. 69, no. 5, pp. 526-537, 2017.

[151] V. Florea, A. C. Rieger, D. L. DiFede et al., "Dose comparison study of allogeneic mesenchymal stem cells in patients with ischemic cardiomyopathy (The TRIDENT Study)," Circulation Research, vol. 121, no. 11, pp. 1279-1290, 2017.

[152] A. W. Heldman, D. L. Difede, J. E. Fishman et al., "Transendocardial mesenchymal stem cells and mononuclear bone marrow cells for ischemic cardiomyopathy: the TAC-HFT randomized trial," JAMA, vol. 311, no. 1, pp. 62-73, 2014.

[153] P. Kharaziha, P. M. Hellström, B. Noorinayer et al., "Improvement of liver function in liver cirrhosis patients after autologous mesenchymal stem cell injection: a phase III clinical trial," European Journal of Gastroenterology and Hepatology, vol. 21, no. 10, pp. 1199-1205, 2009.

[154] W. S. Lee, H. J. Kim, K. I. Kim, G. B. Kim, and W. Jin, "Intraarticular injection of autologous adipose tissue-derived mesenchymal stem cells for the treatment of knee osteoarthritis: a phase IIb, randomized, placebo-controlled clinical trial," Stem Cells Translational Medicine, vol. 8, no. 6, pp. 504511, 2019.

[155] J. Bartolucci, F. J. Verdugo, P. L. González et al., "Safety and efficacy of the intravenous infusion of umbilical cord mesenchymal stem cells in patients with heart failure," Circulation Research, vol. 121, no. 10, pp. 1192-1204, 2017.

[156] A. Trounson, R. G. Thakar, G. Lomax, and D. Gibbons, "Clinical trials for stem cell therapies," BMC Medicine, vol. 9, no. 1, pp. 1-7, 2011.

[157] M. Kim, J.-K. Rhee, H. Choi et al., "Passage-dependent accumulation of somatic mutations in mesenchymal stromal cells during in vitro culture revealed by whole genome sequencing," Scientific Reports, vol. 7, no. 1, pp. 14508-14510, 2017.

[158] V. Nikitina, T. Astrelina, V. Nugis et al., "Clonal chromosomal and genomic instability during human multipotent mesenchymal stromal cells long-term culture," PLoS One, vol. 13, no. 2, article e0192445, 2018.

[159] J. M. S. Cabral, Stem Cell Manufacturing, Elsevier, 2017.

[160] S. Y. Kwon, S. Y. Chun, Y.-S. Ha et al., "Hypoxia enhances cell properties of human mesenchymal stem cells," Tissue Engineering and Regenerative Medicine, vol. 14, no. 5, pp. 595604, 2017.

[161] C. Dessels, C. Durandt, and M. S. Pepper, "Comparison of human platelet lysate alternatives using expired and freshly isolated platelet concentrates for adipose-derived stromal cell expansion," Platelets, vol. 30, no. 3, pp. 356-367, 2019.

[162] S. Wangler, A. Kamali, C. Wapp et al., "Uncovering the secretome of mesenchymal stromal cells exposed to healthy, 
traumatic, and degenerative intervertebral discs: a proteomic analysis," Stem Cell Research \& Therapy, vol. 12, no. 1, p. 11, 2021.

[163] M. Gimona, M. F. Brizzi, A. B. H. Choo et al., "Critical considerations for the development of potency tests for therapeutic applications of mesenchymal stromal cell-derived small extracellular vesicles," Cytotherapy, vol. 23, no. 5, pp. 373380, 2021.

[164] L. Dou, Y. Wu, Q. Yan, J. Wang, Y. Zhang, and P. Ji, “Secretome profiles of immortalized dental follicle cells using iTRAQ-based proteomic analysis," Scientific Reports, vol. 7, no. 1, article ???, 2017.

[165] T. S. Chen, F. Arslan, Y. Yin et al., "Enabling a robust scalable manufacturing process for therapeutic exosomes through oncogenic immortalization of human ESC-derived MSCs," Journal of Translational Medicine, vol. 9, no. 1, p. 47, 2011.

[166] R. Waters, S. Subham, S. Pacelli, S. Modaresi, A. R. Chakravarti, and A. Paul, "Development of MicroRNA-146aEnriched stem cell secretome for wound-healing applications," Molecular Pharmaceutics, vol. 16, no. 10, pp. 43024312, 2019.

[167] R. Giancola, T. Bonfini, and A. Iacone, "Cell therapy: cGMP facilities and manufacturing," Muscles, Ligaments and Tendons Journal, vol. 2, no. 3, pp. 243-247, 2012.

[168] M. Viganò, R. Giordano, and L. Lazzari, "Challenges of running a GMP facility for regenerative medicine in a public hospital," Regenerative Medicine, vol. 12, no. 7, pp. 803-813, 2017.

[169] M. Dominici, K. Le Blanc, I. Mueller et al., "Minimal criteria for defining multipotent mesenchymal stromal cells. The International Society for Cellular Therapy position statement," Cytotherapy, vol. 8, no. 4, pp. 315-317, 2006.

[170] N. Kalinina, D. Kharlampieva, M. Loguinova et al., "Characterization of secretomes provides evidence for adiposederived mesenchymal stromal cells subtypes," Stem Cell Research \& Therapy, vol. 6, no. 1, p. ???, 2015.

[171] K. W. Witwer, B. W. M. Van Balkom, S. Bruno et al., "Defining mesenchymal stromal cell (MSC)-derived small extracellular vesicles for therapeutic applications," Journal of Extracellular Vesicles, vol. 8, no. 1, article 1609206, 2019.

[172] G. Qiu, G. Zheng, M. Ge et al., "Mesenchymal stem cellderived extracellular vesicles affect disease outcomes via transfer of microRNAs," Stem Cell Research \& Therapy, vol. 9, no. 1, p. 320, 2018.

[173] K. Asgarpour, Z. Shojaei, F. Amiri et al., "Exosomal microRNAs derived from mesenchymal stem cells: cell-to-cell messages," Cell Communication and Signaling, vol. 18, no. 1, p. 149, 2020.

[174] K. X. Wang, L. L. Xu, Y. F. Rui et al., "The effects of secretion factors from umbilical cord derived mesenchymal stem cells on osteogenic differentiation of mesenchymal stem cells," PLoS One, vol. 10, no. 3, article e0120593, 2015.

[175] Q. Sun, Z. Zhang, and Z. Sun, "The potential and challenges of using stem cells for cardiovascular repair and regeneration," Genes and Diseases, vol. 1, no. 1, pp. 113-119, 2014.

[176] H. J. Kim and J.-S. Park, "Usage of human mesenchymal stem cells in Cell-based therapy: advantages and disadvantages," Development and Reproduction, vol. 21, no. 1, pp. 110, 2017.

[177] N. V. Katolikova, A. B. Malashicheva, and R. R. Gainetdinov, "Cell replacement therapy in Parkinson's disease-history of development and prospects for use in clinical practice," Molecular Biology, vol. 54, no. 6, pp. 827-839, 2020.

[178] C. Schuetz, T. Anazawa, S. E. Cross et al., “ $\beta$ cell replacement therapy: the next 10 years," Transplantation, vol. 102, no. 2 , pp. 215-229, 2018.

[179] C. Grange, M. Tapparo, S. Bruno et al., "Biodistribution of mesenchymal stem cell-derived extracellular vesicles in a model of acute kidney injury monitored by optical imaging," International Journal of Molecular Medicine, vol. 33, no. 5, pp. 1055-1063, 2014.

[180] Y. Han, D. Seyfried, Y. Meng et al., "Multipotent mesenchymal stromal cell-derived exosomes improve functional recovery after experimental intracerebral hemorrhage in the rat," Journal of Neurosurgery, vol. 131, no. 1, pp. 290-300, 2018.

[181] L. Otero-Ortega, F. Laso-García, M. D. Gómez-de Frutos et al., "White matter repair after extracellular vesicles administration in an experimental animal model of subcortical stroke," Scientific Reports, vol. 7, no. 1, article 44433, 2017.

[182] C. Steingen, F. Brenig, L. Baumgartner, J. Schmidt, A. Schmidt, and W. Bloch, "Characterization of key mechanisms in transmigration and invasion of mesenchymal stem cells," Journal of Molecular and Cellular Cardiology, vol. 44, no. 6, pp. 1072-1084, 2008.

[183] T. Matsushita, T. Kibayashi, T. Katayama et al., "Mesenchymal stem cells transmigrate across brain microvascular endothelial cell monolayers through transiently formed interendothelial gaps," Neuroscience Letters, vol. 502, no. 1, pp. 41-45, 2011.

[184] F. J. Vizoso, N. Eiro, S. Cid, J. Schneider, and R. Perez-Fernandez, "Mesenchymal stem cell secretome: toward cell-free therapeutic strategies in regenerative medicine," International Journal of Molecular Sciences, vol. 18, no. 9, article 1852, 2017.

[185] M. Breitbach, T. Bostani, W. Roell et al., "Potential risks of bone marrow cell transplantation into infarcted hearts," Blood, vol. 110, no. 4, pp. 1362-1369, 2007.

[186] L. Song, N. E. Webb, Y. Song, and R. S. Tuan, "Identification and functional analysis of candidate genes regulating mesenchymal stem cell self-renewal and multipotency," Stem Cells, vol. 24, no. 7, pp. 1707-1718, 2006.

[187] J. Ma, Y. Zhao, L. Sun et al., "Exosomes derived from AKtmodified human umbilical cord mesenchymal stem cells improve cardiac regeneration and promote angiogenesis via activating platelet-derived growth factor D," Stem Cells Translational Medicine, vol. 6, no. 1, pp. 51-59, 2017.

[188] X. P. Xu, L. L. Huang, S. L. Hu et al., "Genetic modification of mesenchymal stem cells overexpressing angiotensin II type 2 receptor increases cell migration to injured lung in LPSinduced acute lung injury mice," Stem Cells Translational Medicine, vol. 7, no. 10, pp. 721-730, 2018.

[189] J. S. Park, S. Suryaprakash, Y.-H. Lao, and K. W. Leong, "Engineering mesenchymal stem cells for regenerative medicine and drug delivery," Methods, vol. 84, pp. 3-16, 2015.

[190] F. A. Fierro, S. Kalomoiris, C. S. Sondergaard, and J. A. Nolta, "Effects on proliferation and differentiation of multipotent bone marrow stromal cells engineered to express growth factors for combined cell and gene therapy," Stem Cells, vol. 29, no. 11, pp. 1727-1737, 2011.

[191] J. Y. Lim, S. I. Park, S. M. Kim et al., "Neural differentiation of brain-derived neurotrophic factor-expressing human umbilical cord blood-derived mesenchymal stem cells in culture via 
TrkB-Mediated ERK and $\beta$-catenin phosphorylation and following transplantation into the developing brain," Cell Transplantation, vol. 20, no. 11-12, pp. 1855-1866, 2011.

[192] V. Scheper, J. Schwieger, A. Hamm, T. Lenarz, and A. Hoffmann, "BDNF-overexpressing human mesenchymal stem cells mediate increased neuronal protection in vitro," Journal of Neuroscience Research, vol. 97, no. 11, pp. 14141429, 2019.

[193] Y. Zhang, R. Li, W. Rong et al., "Therapeutic effect of hepatocyte growth factor-overexpressing bone marrow-derived mesenchymal stem cells on CCl 4-induced hepatocirrhosis," Cell Death \& Disease, vol. 9, no. 12, pp. 1-12, 2018.

[194] S. Zhang, W. Jiang, L. Ma, Y. Liu, X. Zhang, and S. Wang, "Nrf 2 transfection enhances the efficacy of human amniotic mesenchymal stem cells to repair lung injury induced by lipopolysaccharide," Journal of Cellular Biochemistry, vol. 119, no. 2, pp. 1627-1636, 2018.

[195] J. Jiang, D. Wei, L. Sun et al., "A preliminary study on the construction of double suicide gene delivery vectors by mesenchymal stem cells and the in vitro inhibitory effects on SKOV3 cells," Oncology Reports, vol. 31, no. 2, pp. 781-787, 2014.

[196] G. P. Duffy, S. D'Arcy, T. Ahsan, R. M. Nerem, T. O'Brien, and F. Barry, "Mesenchymal stem cells overexpressing ephrin-b2 rapidly adopt an early endothelial phenotype with simultaneous reduction of osteogenic potential," Tissue Engineering Part A, vol. 16, no. 9, pp. 2755-2768, 2010.

[197] Y. J. Chae, D. W. Jun, J. S. Lee et al., "The use of Foxa2Overexpressing adipose tissue-derived stem cells in a scaffold system attenuates acute liver injury," Gut and Liver, vol. 13, no. 4, pp. 450-460, 2019.

[198] W. Wang, Y. Zhang, C. Yang et al., "Transplantation of neuregulin 4-overexpressing adipose-derived mesenchymal stem cells ameliorates insulin resistance by attenuating hepatic steatosis," Experimental Biology and Medicine, vol. 244, no. 7, pp. 565-578, 2019.

[199] W. Huang, T. Wang, D. Zhang et al., "Mesenchymal stem cells overexpressing CXCR4 attenuate remodeling of postmyocardial infarction by releasing matrix metalloproteinase-9," Stem Cells and Development, vol. 21, no. 5, pp. 778789, 2012.

[200] C. Z. Kopru, I. Cagnan, I. Akar, G. Esendagli, P. Korkusuz, and A. Gunel-Ozcan, "Dual Effect of GlucocorticoidInduced Tumor Necrosis Factor-Related Receptor Ligand Carrying Mesenchymal Stromal Cells on Small Cell Lung Cancer: A Preliminary in vitro Study," Cytotherapy, vol. 20, no. 7, pp. 930-940, 2018.

[201] S.-W. Kim, D.-W. Lee, L.-H. Yu et al., "Mesenchymal stem cells overexpressing GCP-2 improve heart function through enhanced angiogenic properties in a myocardial infarction model," Cardiovascular Research, vol. 95, no. 4, pp. 495506, 2012.

[202] M. Kearns-Jonker, W. Dai, M. Gunthart et al., "Genetically engineered mesenchymal stem cells influence gene expression in donor cardiomyocytes and the recipient heart," Journal of Stem Cell Research \& Therapy, vol. 2012, Supplement 1, p. 5, 2012.

[203] Y. S. Song, H. J. Lee, S. H. Doo et al., "Mesenchymal stem cells overexpressing hepatocyte growth factor (HGF) inhibit collagen deposit and improve bladder function in rat model of bladder outlet obstruction," Cell Transplantation, vol. 21, no. 8, pp. 1641-1650, 2012.
[204] L. Zhao, X. Liu, Y. Zhang et al., "Enhanced cell survival and paracrine effects of mesenchymal stem cells overexpressing hepatocyte growth factor promote cardioprotection in myocardial infarction," Experimental Cell Research, vol. 344, no. 1, pp. 30-39, 2016.

[205] L. Lai, J. Chen, X. Wei et al., "Transplantation of MSCs overexpressing HGF into a rat model of liver fibrosis," Molecular Imaging and Biology, vol. 18, no. 1, pp. 43-51, 2016.

[206] J. Li, C.-Q. Zheng, Y. Li, C. Yang, H. Lin, and H.-G. Duan, "Hepatocyte growth factor gene-modified mesenchymal stem cells augment sinonasal wound healing," Stem Cells and Development, vol. 24, no. 15, pp. 1817-1830, 2015.

[207] X.-S. Liu, J.-F. Li, S.-S. Wang et al., "Human umbilical cord mesenchymal stem cells infected with adenovirus expressing HGF promote regeneration of damaged neuron cells in a Parkinson's disease model," BioMed Research International, vol. 2014, Article ID 909657, 7 pages, 2014.

[208] K. W. Seo, S. Y. Sohn, D. H. Bhang, M. J. Nam, H. W. Lee, and H. Y. Youn, "Therapeutic effects of hepatocyte growth factoroverexpressing human umbilical cord blood-derived mesenchymal stem cells on liver fibrosis in rats," Cell Biology International, vol. 38, no. 1, pp. 106-116, 2014.

[209] S. R. Jeong, M. J. Kwon, H. G. Lee et al., "Hepatocyte growth factor reduces astrocytic scar formation and promotes axonal growth beyond glial scars after spinal cord injury," Experimental Neurology, vol. 233, no. 1, pp. 312-322, 2012.

[210] N. Wu, Y.-L. Zhang, H.-T. Wang et al., "Overexpression of hepatocyte nuclear factor $4 \alpha$ in human mesenchymal stem cells suppresses hepatocellular carcinoma development through Wnt/ $\beta$-catenin signaling pathway downregulation," Cancer Biology \& Therapy, vol. 17, no. 5, pp. 558-565, 2016.

[211] E. J. Lee, E.-K. Choi, S. K. Kang et al., "N-cadherin determines individual variations in the therapeutic efficacy of human umbilical cord blood-derived mesenchymal stem cells in a rat model of myocardial infarction," Molecular Therapy, vol. 20, no. 1, pp. 155-167, 2012.

[212] V. Razban, A. S. Lotfi, M. Soleimani et al., "HIF- $1 \alpha$ overexpression induces angiogenesis in mesenchymal stem cells," BioResearch Open Access, vol. 1, no. 4, pp. 174-183, 2012.

[213] N. L. Payne, A. Dantanarayana, G. Sun et al., "Early intervention with gene-modified mesenchymal stem cells overexpressing interleukin-4 enhances anti-inflammatory responses and functional recovery in experimental autoimmune demyelination," Cell Adhesion \& Migration, vol. 6, no. 3, pp. 179-189, 2012.

[214] J. S. Choi, I. S. Jeong, J. H. Han, S. H. Cheon, and S.-W. Kim, "IL-10-secreting human MSCs generated by TALEN gene editing ameliorate liver fibrosis through enhanced antifibrotic activity," Biomaterials Science, vol. 7, no. 3, pp. 1078-1087, 2019.

[215] M. Nakajima, C. Nito, K. Sowa et al., "Mesenchymal stem cells overexpressing interleukin-10 promote neuroprotection in experimental acute ischemic stroke," Molecular TherapyMethods \& Clinical Development, vol. 6, pp. 102-111, 2017.

[216] F. Yang, R. Wu, Z. Jiang et al., "Leptin increases mitochondrial OPA1 via GSK3-mediated OMA1 ubiquitination to enhance therapeutic effects of mesenchymal stem cell transplantation," Cell Death \& Disease, vol. 9, no. 5, pp. 1-17, 2018.

[217] C. Xie, L.-Y. Du, F. Guo, X. Li, and B. Cheng, "Exosomes derived from microRNA-101-3p-overexpressing human bone marrow mesenchymal stem cells suppress oral cancer 
cell proliferation, invasion, and migration," Molecular and Cellular Biochemistry, vol. 458, no. 1-2, pp. 11-26, 2019.

[218] L. Yu, S. Gui, Y. Liu et al., "Exosomes derived from microRNA-199a-overexpressing mesenchymal stem cells inhibit glioma progression by down-regulating AGAP2," Aging, vol. 11, no. 15, pp. 5300-5318, 2019.

[219] G. Zhu, L. Pei, F. Lin et al., "Exosomes from human-bonemarrow-derived mesenchymal stem cells protect against renal ischemia/reperfusion injury via transferring miR199a-3p," Journal of Cellular Physiology, vol. 234, no. 12, pp. 23736-23749, 2019.

[220] L. Huleihel, J. Sellares, N. Cardenes et al., "Modified mesenchymal stem cells using mi RNA transduction alter lung injury in a bleomycin model," American Journal of Physiology-Lung Cellular and Molecular Physiology, vol. 313, no. 1, pp. L92-L103, 2017.

[221] Z. Wei, S. Qiao, J. Zhao et al., "miRNA-181a over-expression in mesenchymal stem cell-derived exosomes influenced inflammatory response after myocardial ischemiareperfusion injury," Life Sciences, vol. 232, article 116632, 2019.

[222] S. Ryu, J.-M. Lee, C. A. Bae, C.-E. Moon, and K.-O. Cho, "Therapeutic efficacy of neuregulin 1-expressing human adipose-derived mesenchymal stem cells for ischemic stroke," PloS One, vol. 14, no. 9, article e0222587, 2019.

[223] S.-M. Han, S.-H. Han, Y.-R. Coh et al., "Enhanced proliferation and differentiation of Oct4- and Sox2-overexpressing human adipose tissue mesenchymal stem cells," Experimental \& Molecular Medicine, vol. 46, no. 6, article e101, 2014.

[224] A. Bonilla-Porras, A. Arevalo-Arbelaez, J. Alzate-Restrepo, C. Velez-Pardo, and M. Jimenez-Del-Rio, "PARKIN overexpression in human mesenchymal stromal cells from Wharton's jelly suppresses 6-hydroxydopamine-induced apoptosis: Potential therapeutic strategy in Parkinson's disease," Cytotherapy, vol. 20, no. 1, pp. 45-61, 2018.

[225] Y. Gao, A. Yao, W. Zhang et al., "Human mesenchymal stem cells overexpressing pigment epithelium-derived factor inhibit hepatocellular carcinoma in nude mice," Oncogene, vol. 29, no. 19, pp. 2784-2794, 2010.

[226] M. Ji, W. Wang, S. Li, and W. Hu, "Implantation of bone mesenchymal stem cells overexpressing miRNA-705 mitigated ischemic brain injury," Molecular Medicine Reports, vol. 16, no. 6, pp. 8323-8328, 2017.

[227] I. Martínez-González, M.-J. Cruz, R. Moreno, F. Morell, X. Muñoz, and J. M. Aran, "Human mesenchymal stem cells resolve airway inflammation, hyperreactivity, and histopathology in a mouse model of occupational asthma," Stem Cells and Development, vol. 23, no. 19, pp. 2352-2363, 2014.

[228] I. Martínez-González, O. Roca, J. R. Masclans et al., "Human mesenchymal stem cells overexpressing the IL-33 antagonist soluble IL-1 receptor-like-1 attenuate endotoxin-induced acute lung injury," American Journal of Respiratory Cell and Molecular Biology, vol. 49, no. 4, pp. 552-562, 2013.

[229] J. Hu, Z. Yang, J. Wang et al., "Infusion of Trx-1overexpressing huc MSC prolongs the survival of acutely irradiated NOD/SCID mice by decreasing excessive inflammatory injury," PLoS One, vol. 8, no. 11, article e78227, 2013.

[230] J. Ni, X. Liu, Y. Yin, P. Zhang, Y.-W. Xu, and Z. Liu, "Exosomes Derived from TIMP2-Modified Human Umbilical Cord Mesenchymal Stem Cells Enhance the Repair Effect in Rat Model with Myocardial Infarction Possibly by the
Akt/Sfrp2 Pathway," Oxidative Medicine and Cellular Longevity, vol. 2019, Article ID 1958941, 19 pages, 2019.

[231] P. Xia, W. Wang, and Y. Bai, "Claudin-7 suppresses the cytotoxicity of TRAIL-expressing mesenchymal stem cells in H460 human non-small cell lung cancer cells," Apoptosis, vol. 19, no. 3, pp. 491-505, 2014.

[232] X. Jiang, S. Fitch, C. Wang et al., "Nanoparticle engineered TRAIL-overexpressing adipose-derived stem cells target and eradicate glioblastoma via intracranial delivery," Proceedings of the National Academy of Sciences, vol. 113, no. 48, pp. 13857-13862, 2016.

[233] C. Spano, G. Grisendi, G. Golinelli et al., "Soluble TRAIL armed human MSC as gene therapy for pancreatic cancer," Scientific Reports, vol. 9, no. 1, pp. 1-14, 2019.

[234] A. J. Man, G. Kujawski, T. S. Burns et al., "Neurogenic potential of engineered mesenchymal stem cells overexpressing VEGF," Cellular and Molecular Bioengineering, vol. 9, no. 1, pp. 96-106, 2016.

[235] Z. Cheng, L. Ou, X. Zhou et al., "Targeted migration of mesenchymal stem cells modified with CXCR4 gene to infarcted myocardium improves cardiac performance," Molecular Therapy, vol. 16, no. 3, pp. 571-579, 2008.

[236] Y. L. Tang, Y. Tang, Y. C. Zhang, K. Qian, L. Shen, and M. I. Phillips, "Improved graft mesenchymal stem cell survival in ischemic heart with a hypoxia-regulated heme oxygenase-1 vector," Journal of the American College of Cardiology, vol. 46, no. 7, pp. 1339-1350, 2005.

[237] W. Li, N. Ma, L. L. Ong et al., "Bcl-2 engineered MSCs inhibited apoptosis and improved heart function," Stem Cells, vol. 25, no. 8, pp. 2118-2127, 2007.

[238] A. A. Mangi, N. Noiseux, D. Kong et al., "Mesenchymal stem cells modified with Akt prevent remodeling and restore performance of infarcted hearts," Nature Medicine, vol. 9, no. 9, pp. 1195-1201, 2003.

[239] J. K. Burkus, E. E. Transfeldt, S. H. Kitchel, R. G. Watkins, and R. A. Balderston, "Clinical and radiographic outcomes of anterior lumbar interbody fusion using recombinant human bone morphogenetic protein-2," Spine, vol. 27, no. 21, pp. 2396-2408, 2002.

[240] J. Fang, Y.-Y. Zhu, E. Smiley et al., "Stimulation of new bone formation by direct transfer of osteogenic plasmid genes," Proceedings of the National Academy of Sciences, vol. 93, no. 12, pp. 5753-5758, 1996.

[241] R. Franceschi, "Biological approaches to bone regeneration by gene therapy," Journal of Dental Research, vol. 84, no. 12, pp. 1093-1103, 2005.

[242] Y. Liu, X. Z. Shu, and G. D. Prestwich, "Osteochondral defect repair with autologous bone marrow-derived mesenchymal stem cells in an injectable, in situ, cross-linked synthetic extracellular matrix," Tissue Engineering, vol. 12, no. 12, pp. 3405-3416, 2006.

[243] E. Syková, P. Jendelová, L. Urdzíková, P. Lesný, and A. Hejčl, "Bone marrow stem cells and polymer hydrogels-two strategies for spinal cord injury repair," Cellular and Molecular Neurobiology, vol. 26, no. 7-8, pp. 1111-1127, 2006.

[244] Q. Tu, P. Valverde, S. Li, J. Zhang, P. Yang, and J. Chen, "Osterix overexpression in mesenchymal stem cells stimulates healing of critical-sized defects in murine calvarial bone," Tissue Engineering, vol. 13, no. 10, pp. 2431-2440, 2007.

[245] A. Hoffmann, G. Pelled, G. Turgeman et al., "Neotendon formation induced by manipulation of the Smad 8 signalling 
pathway in mesenchymal stem cells," The Journal of Clinical Investigation, vol. 116, no. 4, pp. 940-952, 2006.

[246] C.-A. Guo, X.-G. Liu, J.-Z. Huo, C. Jiang, X.-J. Wen, and Z.R. Chen, "Novel gene-modified-tissue engineering of cartilage using stable transforming growth factor- $\beta 1$-transfected mesenchymal stem cells grown on chitosan scaffolds," Journal of Bioscience and Bioengineering, vol. 103, no. 6, pp. 547-556, 2007.

[247] A. J. Engler, S. Sen, H. L. Sweeney, and D. E. Discher, "Matrix elasticity directs stem cell lineage specification," Cell, vol. 126, no. 4 , pp. 677-689, 2006.

[248] J. M. Curran, R. Chen, and J. A. Hunt, "The guidance of human mesenchymal stem cell differentiation in vitro by controlled modifications to the cell substrate," Biomaterials, vol. 27, no. 27, pp. 4783-4793, 2006.

[249] C. O. Cassell, O. S. Hofer, W. A. Morrison, and K. R. Knight, "Vascularisation of tissue-engineered grafts: the regulation of angiogenesis in reconstructive surgery and in disease states," British Journal of Plastic Surgery, vol. 55, no. 8, pp. 603-610, 2002.

[250] J. Rouwkema, J. D. Boer, and C. A. V. Blitterswijk, "Endothelial cells assemble into a 3-dimensional prevascular network in a bone tissue engineering construct," Tissue Engineering, vol. 12, no. 9, pp. 2685-2693, 2006.

[251] N. de Cássia Noronha, A. Mizukami, C. Caliári-Oliveira et al., "Priming approaches to improve the efficacy of mesenchymal stromal cell-based therapies," Stem Cell Research \& Therapy, vol. 10, no. 1, pp. 1-21, 2019.

[252] M. Mendt, S. Kamerkar, H. Sugimoto et al., "Generation and testing of clinical-grade exosomes for pancreatic cancer," JCI Insight, vol. 3, no. 8, article e99263, 2018.

[253] A. Datta, H. Kim, L. McGee et al., "High-throughput screening identified selective inhibitors of exosome biogenesis and secretion: a drug repurposing strategy for advanced cancer," Scientific Reports, vol. 8, no. 1, pp. 1-13, 2018.

[254] K. Laulagnier, D. Grand, A. Dujardin et al., "PLD2 is enriched on exosomes and its activity is correlated to the release of exosomes," FEBS Letters, vol. 572, no. 1-3, pp. 11-14, 2004.

[255] H.-C. Zhang, X.-B. Liu, S. Huang et al., "Microvesicles derived from human umbilical cord mesenchymal stem cells stimulated by hypoxia promote angiogenesis both in vitro and in vivo," Stem Cells and Development, vol. 21, no. 18, pp. 3289-3297, 2012.

[256] C. Almeria, R. Weiss, M. Roy et al., "Hypoxia conditioned mesenchymal stem cell-derived extracellular vesicles induce increased vascular tube formation in vitro," Frontiers In Bioengineering and Biotechnology, vol. 7, p. 292, 2019.

[257] C. Xue, Y. Shen, X. Li et al., "Exosomes derived from hypoxiatreated human adipose mesenchymal stem cells enhance angiogenesis through the PKA signaling pathway," Stem Cells and Development, vol. 27, no. 7, pp. 456-465, 2018.

[258] S. C. Lee, H. J. Jeong, S. K. Lee, and S.-J. Kim, "Lipopolysaccharide preconditioning of adipose-derived stem cells improves liver-regenerating activity of the secretome," Stem Cell Research \& Therapy, vol. 6, no. 1, pp. 1-11, 2015.

[259] D. Ti, H. Hao, C. Tong et al., "LPS-preconditioned mesenchymal stromal cells modify macrophage polarization for resolution of chronic inflammation via exosome-shuttled let-7b," Journal of Translational Medicine, vol. 13, no. 1, pp. 1-14, 2015.
[260] J. A. Kink, M. H. Forsberg, S. Reshetylo et al., "Macrophages educated with exosomes from primed mesenchymal stem cells treat acute radiation syndrome by promoting hematopoietic recovery," Biology of Blood and Marrow Transplantation, vol. 25, no. 11, pp. 2124-2133, 2019.

[261] F. A. Alzahrani, "Melatonin improves therapeutic potential of mesenchymal stem cells-derived exosomes against renal ischemia-reperfusion injury in rats," American Journal of Translational Research, vol. 11, no. 5, article 2887, 2019.

[262] J. Ding, X. Wang, B. Chen, J. Zhang, and J. Xu, "Exosomes derived from human bone marrow mesenchymal stem cells stimulated by deferoxamine accelerate cutaneous wound healing by promoting angiogenesis," BioMed Research International, vol. 2019, Article ID 9742765, 12 pages, 2019.

[263] H. Li, S. Zuo, Z. He et al., "Paracrine factors released by GATA-4 overexpressed mesenchymal stem cells increase angiogenesis and cell survival," American Journal of Physiology-Heart and Circulatory Physiology, vol. 299, no. 6, article H1772, 2010.

[264] J.-G. He, H.-R. Li, J.-X. Han et al., "GATA-4-expressing mouse bone marrow mesenchymal stem cells improve cardiac function after myocardial infarction via secreted exosomes," Scientific Reports, vol. 8, no. 1, pp. 1-11, 2018.

[265] B. Yu, H. W. Kim, M. Gong et al., "Exosomes secreted from GATA-4 overexpressing mesenchymal stem cells serve as a reservoir of anti-apoptotic microRNAs for cardioprotection," International Journal of Cardiology, vol. 182, pp. 349-360, 2015.

[266] K. Kang, R. Ma, W. Cai et al., "Exosomes secreted from CXCR4 overexpressing mesenchymal stem cells promote cardioprotection via Akt signaling pathway following myocardial infarction," Stem Cells International, vol. 2015, Article ID 659890, 14 pages, 2015.

[267] X. H. Gong, H. Liu, S. J. Wang, S. W. Liang, and G. G. Wang, "Exosomes derived from SDF1-overexpressing mesenchymal stem cells inhibit ischemic myocardial cell apoptosis and promote cardiac endothelial microvascular regeneration in mice with myocardial infarction," Journal of Cellular Physiology, vol. 234, no. 8, pp. 13878-13893, 2019.

[268] D. Cui, "Advances and prospects on biomolecules functionalized carbon nanotubes," Journal of Nanoscience and Nanotechnology, vol. 7, no. 4, pp. 1298-1314, 2007.

[269] D. Pantarotto, R. Singh, D. McCarthy et al., "Functionalized carbon nanotubes for plasmid DNA gene delivery," Angewandte Chemie, vol. 116, no. 39, pp. 5354-5358, 2004.

[270] Q. Lu, J. M. Moore, G. Huang et al., "RNA polymer translocation with single-walled carbon nanotubes," Nano Letters, vol. 4, no. 12, pp. 2473-2477, 2004.

[271] D. Cui, F. Tian, C. S. Ozkan, M. Wang, and H. Gao, "Effect of single wall carbon nanotubes on human HEK293 cells," Toxicology Letters, vol. 155, no. 1, pp. 73-85, 2005. 